\title{
Sensory Schwann cells are required for mechanical nociception and touch perception
}

Julia Ojeda-Alonso ${ }^{1 \dagger}$, Laura Calvo-Enrique ${ }^{2,4 \dagger}$, Ricardo Paricio-Montesinos ${ }^{3}$, Rakesh Kumar $^{2,5}$, Ming-Dong Zhang ${ }^{2}$, James F.A. Poulet, Patrik Ernfors ${ }^{2^{*}}$, Gary R. Lewin ${ }^{1^{*}}$

${ }^{1}$ Molecular Physiology of Somatic Sensation, Max Delbrück Center for Molecular Medicine, Berlin, Germany.

${ }^{2}$ Department of Medical Biochemistry and Biophysics, Division of Molecular Neurobiology, Karolinska Institutet, Stockholm, Sweden.

${ }^{3}$ Neural Circuits and Behavior, Max Delbrück Center for Molecular Medicine, Berlin, Germany.

${ }^{4}$ Present address: Departamento de Biología Celular y Patología, Instituto de Neurociencias de Castilla y León, University of Salamanca, Spain.

${ }^{5}$ Present address: School of Studies in Neuroscience, Jiwaji University, Gwalior, Madhya Pradesh, India

†These authors contributed equally to this work.

*Correspondence to: glewin@mdc-berlin.de or patrik.ernfors@ki.se 
That sensory neurons alone transduce mechanical stimuli was challenged by the discovery of nociceptive Schwann cells that can initiate pain. Consistent with the existence of inherently mechanosensitive sensory Schwann cells, we found that mechanosensory function of almost all nociceptors, including those signaling fast pain were critically dependent on sensory Schwann cells. Furthermore, in polymodal nociceptors, sensory Schwann cells signal mechanical, but not cold or heat pain. Terminal Schwann cells also surround mechanoreceptor nerveendings forming Meissner's corpuscles that signal vibrotactile touch, raising the possibility that touch sensation is also dependent on such cells. Using optogenetics we show that Meissner's corpuscle Schwann cells are necessary for the detection and perception of vibrotactile stimuli. Our results show that sensory Schwann cells within diverse glio-neural mechanosensory end-organs are sensors for mechanical pain as well as touch perception. These results place specialized sensory Schwann cells at the center of somatic sensation to all types of mechanical stimuli.

Touch and pain sensations are conveyed by sensory neurons with their cell bodies in the dorsal root ganglia (DRG). DRG neurons can be broadly classified as mechanoreceptors responsible for touch sensation or nociceptors which detect harmful mechanical, thermal and chemical stimuli ${ }^{1}$. The last three decades have seen huge advances in the discovery of nociceptor-specific ion channels and other signaling molecules that may be targeted to control pain ${ }^{2-4}$. More recently molecules necessary for normal mammalian touch sensation have also been identified ${ }^{5,6}$. Such studies were predicated on the idea that the transduction of mechanical stimuli takes place primarily at the sensory neuron membrane. Consistent with this idea many studies have shown that cultured sensory neurons, whether mechanoreceptors or nociceptors, are mechanosensitive in that mechanical stimuli activate fast inward currents in these cells ${ }^{7-10}$. This paradigm, placing the nociceptive neuron at the center of pain control, was recently challenged by the finding that specialized nociceptive Schwann cells expressing the transcription factor Sox10 are tightly associated with sensory endings and can initiate pain ${ }^{11,12}$. Sox $10^{+}$Schwann cells are also found associated with mechanoreceptor endings in skin end-organs needed for touch sensation ${ }^{7,13,14}$. Here, 
we used optogenetic tools to directly assess the contribution of Sox $10^{+}$terminal Schwann cells to the transduction of mechanical pain and the perception of touch.

A
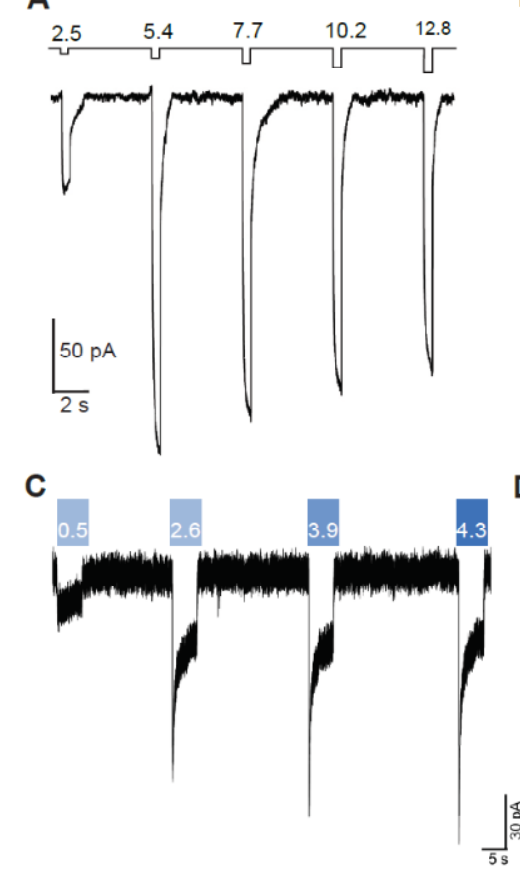

E

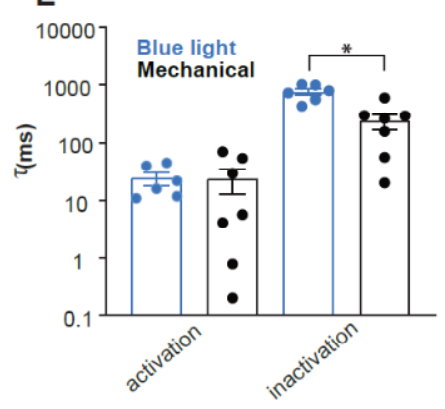

B

D

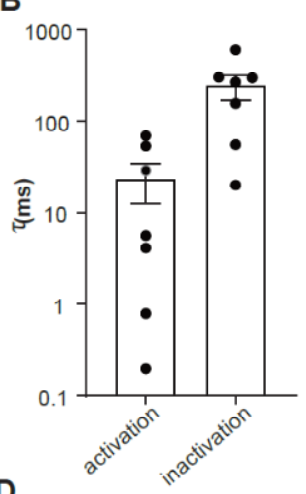

1200

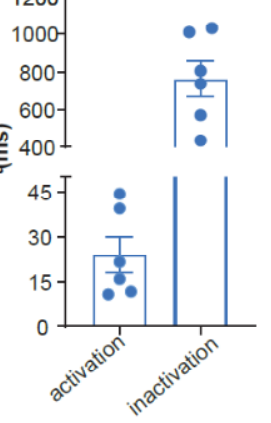

$\mathbf{F}$

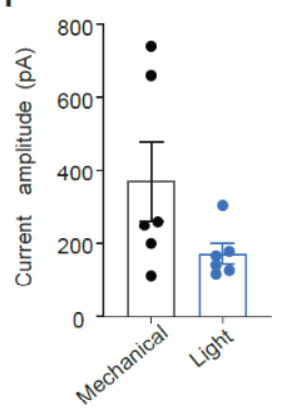

Fig. 1. Schwann cells generate transient currents by mechanical or optogenetic stimulation. (A) Current traces evoked by increasing indentation stimuli in Schwann cells. Step displacement is pictured on top of the traces. (B) Current kinetics of activation $\left(T_{1}\right)$ and inactivation $\left(T_{2}\right)$ to mechanical stimulation. Data are displayed as individual values $(n=7)$, activation $23 \pm 11 \mathrm{~ms}$, decay $243 \pm 74 \mathrm{~ms}$, Mean \pm SEM. (C) Example traces of optogenetically activated currents (top, light intensity in $\mathrm{mW} / \mathrm{mm}^{2}$ ) in cultured terminal Schwann cells expressing channelrhodopsin-2 (2 DIV). (D) Activation and inactivation constants ( $\mathrm{T}$ ) after blue light stimulation at saturating power $\left(4.3 \mathrm{~mW} / \mathrm{mm}^{2}\right)$ in Sox $10-\mathrm{ChR}^{+}$, Data are displayed as individual values $(n=6)$, activation $24 \pm 5.9 \mathrm{~ms}$, decay $765 \pm 97 \mathrm{~ms}$, Mean \pm SEM. (E) Comparison of activation and inactivation constants to blue light (in blue) and mechanical stimulation (in gray). $\mathrm{P}=0.0011$ two-tailed, unpaired $t$ test. (F) Current amplitude values. Schwann cells tended to show larger currents in response to mechanical compared to blue light stimulation, but this not statistically different. 
We generated mice expressing channelrhodopsin (ChR2) or Archaerhodopsin (ArchT) in Sox10-positive terminal Schwann cells to excite or inhibit these cells with light. We made whole cell voltage clamp recordings from cultured skin Schwann cells from Sox10-TOM and Sox10-ChR2 mice and using a poking protocol ${ }^{7}$ we evoked large inward currents that inactivated slowly (Fig 1A,B), confirming that these cells are indeed mechanosensitive ${ }^{7}$. We also used blue light to activate photo currents in Sox10-ChR2positive Schwann cells and could measure large rapidly activating currents that inactivated only slowly in the presence of light (Fig 1C,D). Blue light evoked photo currents were of similar magnitude and had similar kinetics to mechanically activated currents in Sox10-ChR2-positive Schwann cells (Fig. 1E,F). We conclude that light can be used as a surrogate for mechanical stimulation to selectively manipulate the activity of sensory Schwann cells in vivo.

Light stimulation of nociceptive Schwann cells provokes nocifensive behaviors ${ }^{7}$. Nociceptive Schwann cells are innervated by both thinly myelinated (Aס-fiber) and unmyelinated (C-fiber) sensory axons which have diverse receptor properties ${ }^{1}$. Classically, many C-fiber nociceptors are polymodal responding to both mechanical and thermal stimuli ${ }^{1,15,16}$, but even polymodal nociceptors can contribute to non-noxious cool and warm perception ${ }^{16,17}$. Using an ex vivo preparation ${ }^{7,18}$ we recorded from identified nociceptors to determine the contribution of sensory Schwann cells to nociceptor function (Fig. 2A). In Sox10-ChR2 mice, blue light tonically activated all four types of nociceptors recorded: Aס-mechanonociceptors (A-Ms), C-mechanonociceptors (C-M responding only mechanical stimuli), polymodal nociceptors, including $\mathrm{C}-\mathrm{MH}$ (Cmechanoheat), C-MC (C-mechanocold) or C-MHC (C-mechanoheatcold) nociceptors that respond to mechanical, cold, heat or both ${ }^{16}$, and C-thermoreceptors (responding to thermal, but not mechanical stimuli) (Fig. 2B-E, Extended Data Fig. 1A). Around 50\% of A-Ms and C-M fibers tested were excited by blue light, but responses were substantially smaller compared to those evoked by supramaximal mechanical stimuli (Fig. 2 F,G Extended Data Fig. 1A-C). In contrast, almost all polymodal nociceptors and around half of the C-M nociceptors were robustly driven by blue light with similar firing frequencies to those evoked by supramaximal mechanical stimuli (Fig. 2B,C,D,G Extended Data Fig 1B,C). Interestingly, activity in both $\mathrm{C}-\mathrm{M}$ and polymodal nociceptors was often driven 
with significantly shorter latencies (just 1-2 ms) than mechanically evoked responses, reflecting a particularly tight coupling between the nociceptive Schwann cell and C-fiber ending (Fig. 2E). C-fibers that only responded to thermal stimuli were all strongly driven by blue light, albeit with very long latencies (Fig. 2D,E,H). Blue light responsive and non-responsive C-M and A-M fibers showed similar sensitivities to mechanical stimuli (Extended Data Fig. 1E,F).

To test the contribution of nociceptive Schwann cells to endogenous mechanosensitivity we compared the response of nociceptors to a supramaximal mechanical stimulus and thermal stimuli before and after a 10-minute exposure to yellow light in Sox10-ArchT mice compared to Sox10-Cre mice, lacking ArchT (Fig. 2I). Of the A-M fibers subjected to light $60 \%$ (6/10 fibers) displayed an elevation in threshold and reduction in mechanically evoked activity (>20\% reduction) (Fig. 2I,J Extended Data Fig. 2A). In comparison, none of the A-Ms recorded from mice lacking ArchT expression $(\mathrm{N}=6)$ displayed any change in threshold or mechanically evoked activity during the same period (Fig. 2l). There was a more than 50\% reduction in mechanosensitivity in AMs recorded from Sox10-ArchT mice which was different compared to controls (AMs from Sox10-Cre mice) at 10 and 20 minutes following yellow light, Two-way ANOVA, P < 0.020, Bonferroni's multiple comparison test (Fig. 2J). We also examined all C-fibers with a mechanosensitive receptive field (C-Ms and polymodal C-fibers). More than 65\% $(\mathrm{N}=22 / 33)$ of these afferents showed a $>20 \%$ reduction in mechanical evoked activity after yellow light exposure in Sox10-ArchT mice (Extended Data Fig. 2A), however, Cfibers recorded from Sox10-Cre controls showed no change ( $\mathrm{N}=11)$ (Fig. 2K). The mean C-fiber mechanosensitivity was reduced by more than $50 \%$ and this was statistically significant compared to controls (C-fibers from Sox10-Cre mice) immediately after yellow light and 10 and 20 minutes later Two-way ANOVA, $P<0.001$, Bonferroni's multiple comparison test (Fig. 2K). Nociceptors in which there was no effect of yellow light had mechanical thresholds and stimulus response properties identical to modulated neurons (Extended Data Fig. 2B-H). Both polymodal and C-thermoreceptors respond to cooling or heating of the skin. We quantified thermally evoked activity in the same C-fibers recorded from Sox10-ArchT ( $N=28 \mathrm{C}$-fibers) and Sox10-Cre mice ( $\mathrm{N}=15$ 
C-fibers) before and after yellow light and observed no change in thermally driven activity up to 20 minutes after yellow light exposure (Fig. 2L, Extended Data Fig. 3). Thus, transduction of thermal stimuli was unchanged in the same C-fibers that showed substantial reductions in mechanically evoked activity (Extended Data Fig. 2E,F). Thus nociceptor Schwann cells are selectively involved in the transduction of mechanical stimuli with thermal sensitivity likely transduced by ion channels located in the neuronal nociceptor membrane.
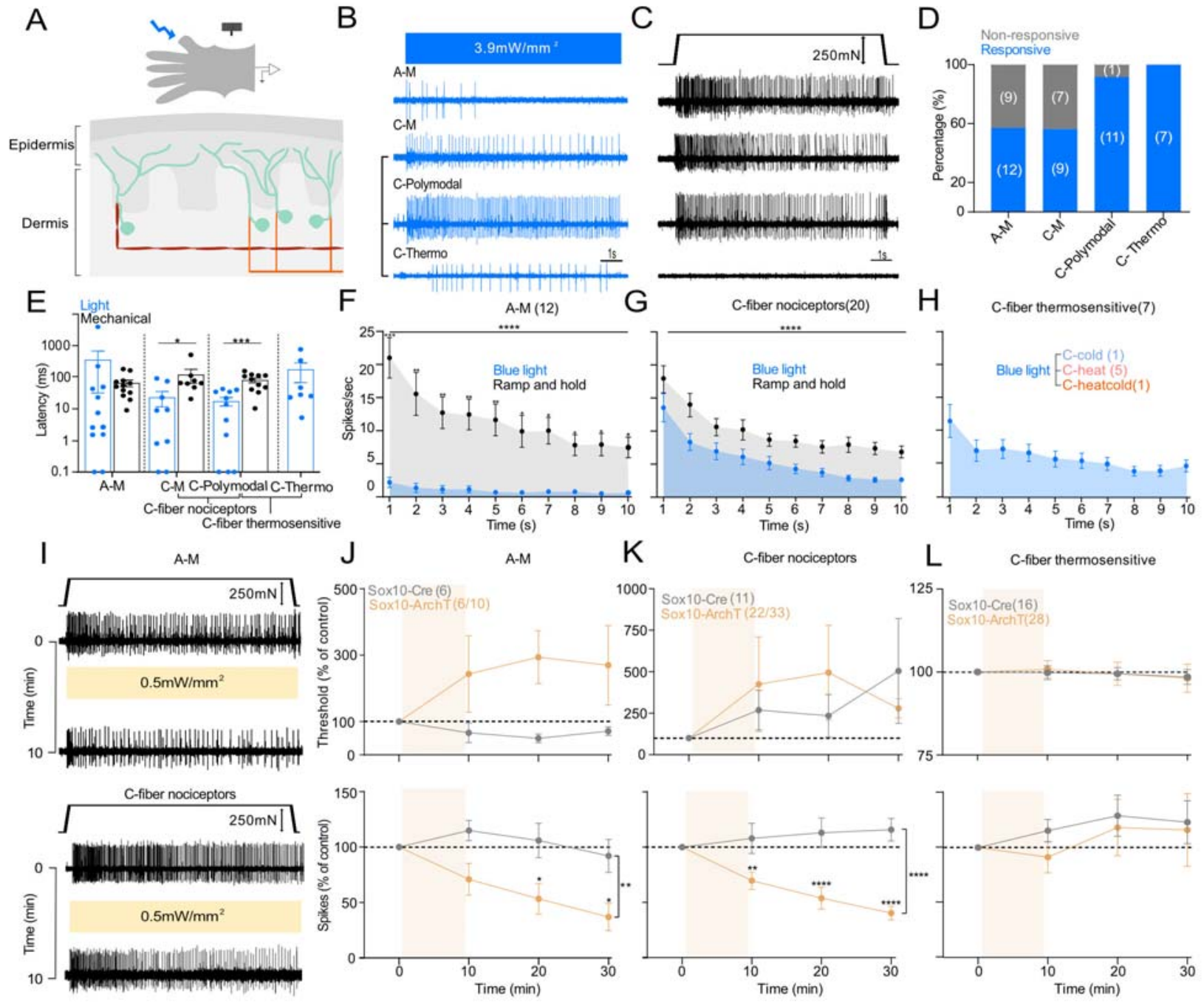

Fig. 2. Nociceptive Schwann cells are required for nociceptor mechanosensitivity. (A) Schematic diagram of ex vivo preparation used to stimulate nociceptive Schwann cells with light (B-C) Example traces of nociceptor types recorded. Activity was recorded after blue light stimulation (B). Spiking of the same nociceptor as in $\mathbf{A}$ to mechanical ramp and hold stimulation (10 s) (C). (D) Proportion of nociceptors responding to blue light. (E) Latency of response to blue light compared to mechanical ramp and hold stimuli. (F-H) Mean time course of nociceptor activation (1 s bins, $10 \mathrm{~s}, 250 \mathrm{mN}$ amplitude ramp and hold stimulus), A-M (F), C-fiber nociceptors (G), and C-fibers with only thermal sensitivity(H). Mean spiking 
rates of the same receptors to blue light (blue) and mechanical stimuli (grey). (I) Representative traces show A-M and C-fiber mechanonociceptor activity to mechanical stimuli (10 s ramp and hold) before and after 10 minutes of yellow light (I). (J) A-M-nociceptors threshold and spiking rates to mechanical stimuli before and after yellow light in Sox10-ArchT mice. (two-way ANOVA, $\mathrm{P}<0.020$, Bonferroni's multiple comparison test). (K) C-fiber nociceptors threshold and spiking rates to mechanical stimuli before and after yellow light in Sox10-ArchT mice. (L) Thermal evoked activity from C-fibers (Polymodal and Cthermoreceptors pooled) to temperature stimulation (heating and cooling ramps $2^{\circ} \mathrm{C} / \mathrm{s}$ ), before and after yellow light in Sox10-ArchT mice (two-way ANOVA, $P<0.001$, Bonferroni's multiple comparison test).

Sox10-TOM-labeled cells were also found within Meissner's corpuscles (Fig. 3A) and hair follicles ${ }^{11}$. In most Meissner's corpuscles we found 2-4 Sox10-TOM ${ }^{+}$cells to be intimately associated with the sensory endings of rapidly-adapting mechanoreceptors (RAMs), that are required for fine touch perception in mice and humans ${ }^{7,13,14,19}$. We used blue light to selectively activate Schwann cells in the glabrous or hairy skin whilst making single-unit recordings from RAMs (Aß-fibers innervating Meissner's corpuscles, or Aß-fibers innervating hair follicles). In Sox10-ChR2 mice blue light reliably evoked 1-2 ultra-short latency spikes in 35\% of the glabrous skin RAMs, but only activated $15 \%$ of RAMs in hairy skin (3/20)(Fig. 3B-E Extended Data Fig. 4A-B). Interestingly, SAMs were never activated by blue light in the glabrous or hairy skin of Sox10-ChR2 mice (Fig. 3B). To evaluate the contribution of Corpuscle resident Schwann cells to mechanosensitivity we compared light-evoked activity with activation by mechanical stimuli in the same neuron (Fig. 3E,F). Ramp and hold mechanical stimuli evoke RAM activity only during the ramp phase of the stimulus as these receptors primarily function as movement sensors ${ }^{7,18,19}$. For glabrous skin RAMs the first spike latencies to blue light stimulation of RAMs in Sox10-ChR2 mice were significantly faster (mean $2.8 \pm 0.7 \mathrm{~ms}$ ) than mechanically evoked spikes (9.3 $\pm 1.8 \mathrm{~ms}, \mathrm{P}<0.01$ unpaired t-test) (Fig. 3C). Blue light activation has an almost instantaneous rise time whereas the Piezo actuator moved at a finite velocity $(15 \mathrm{~mm} / \mathrm{s})$, limiting the speed at which the receptor can reach firing threshold. The extremely short latencies for light activation suggest a tight coupling between $\mathrm{SOX}_{10}{ }^{+}$Schwann cells and the RAM receptor ending. Merkel cells are epidermally derived cells that themselves contribute to the static phase of SAM responses ${ }^{20-22}$. Blue light reliably evoked tonic discharges in $\sim 30 \%$ of SAMs tested from Sox2-ChR2 mice consistent with the expression of Sox2 in Merkel cells (Fig. 3B,C). In contrast to the extremely rapid activation of RAMs by blue light in Sox10-ChR2 mice, blue light stimulation of SAMs in Sox2-ChR2 mice evoked spikes with much 
longer latencies, mean latencies $>300 \mathrm{~ms}$, consistent with coupling mediated by release of a transmitter like substance suggested for Merkel cells ${ }^{23}$. A comparison of firing rates and adaptation for light and mechanical stimuli revealed a remarkably similar profile for RAMs using Sox10-ChR10 in both glabrous and hairy skin (Fig. 3D,E, Extended Data Fig. 4A-C). The stimulus-response properties of RAMs activated or not activated by blue light were identical (Extended Data Fig. 4).

A
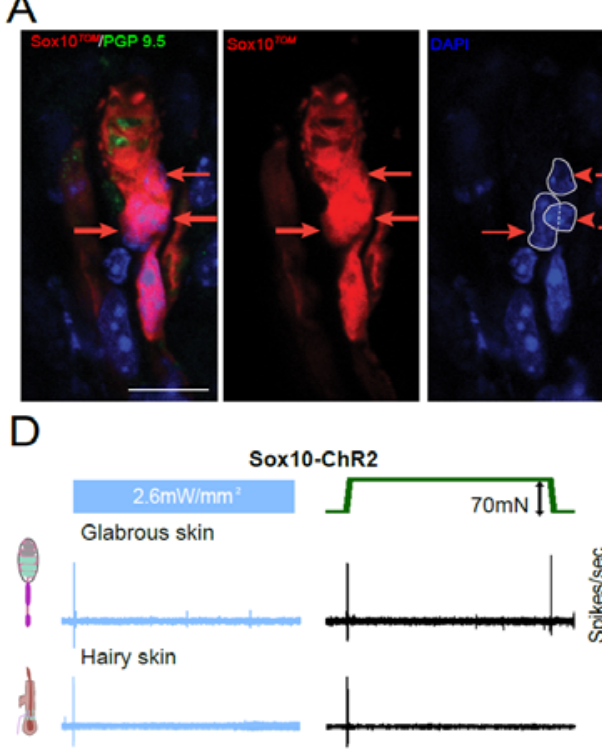

G

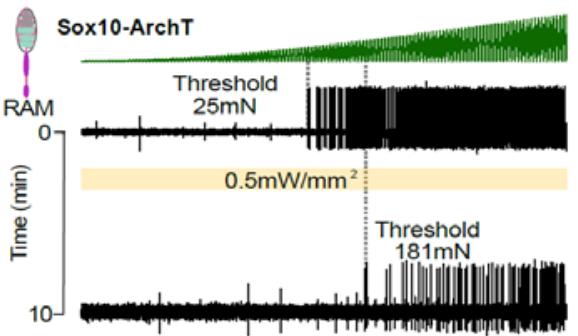

B
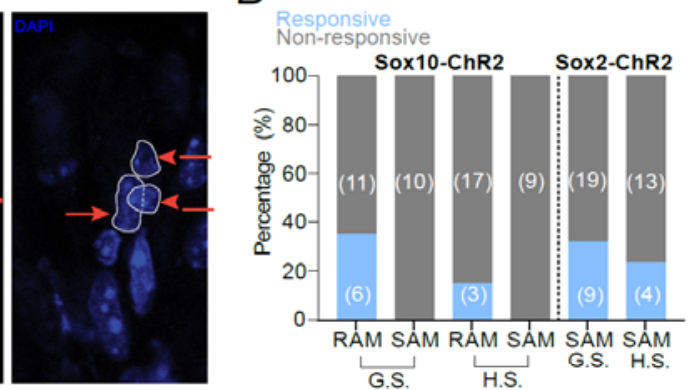

E

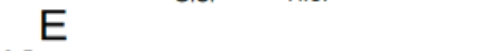

C
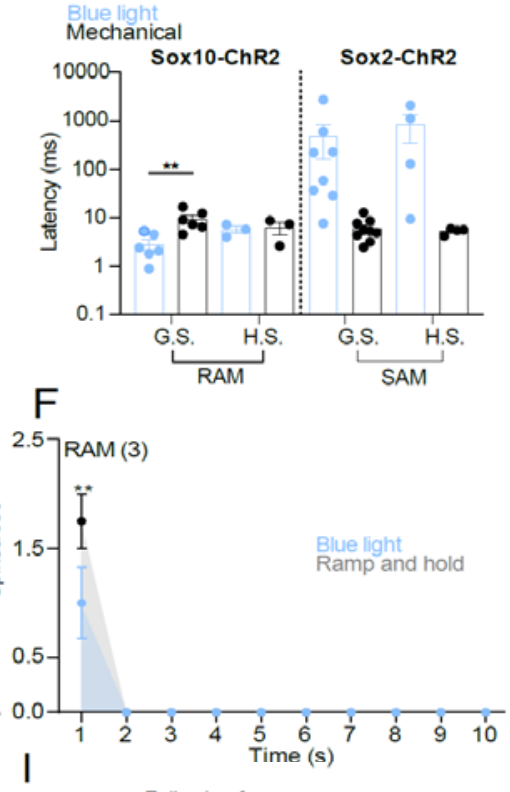

$\mathrm{H}$

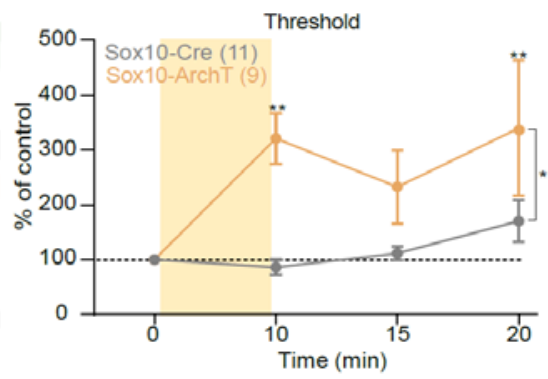

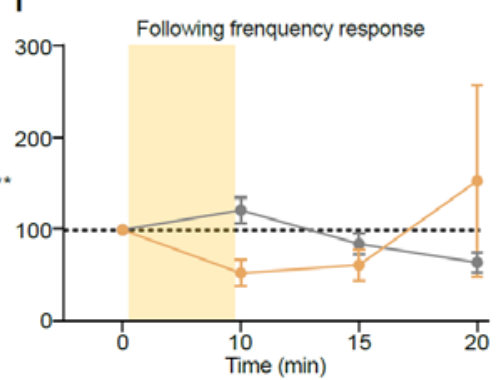

Fig. 3. Sensory Schwann cells in the Meissner's corpuscle are required for vibration sensing. (A) Recombination in glial cells of Meissner corpuscles in Sox10-TOM mice. Immunohistochemistry for TOMATO (recapitulating Sox10 expression) and PGP9.5 to label the corpuscle sensory ending. Arrows point to nuclei from recombined cells in the corpuscle. Scale bar: $20 \mu \mathrm{m}$. (B) Total number of mechanoreceptors (RAM and SAM) recorded from the hairy (H.S.) or glabrous skin (G.S) in Sox10-ChR2 mice, showing proportions of light responsive (blue) and non-responsive fibers (gray) mechanoreceptors (C) First spike latencies for RAM and SAM mechanoreceptors comparing optogenetic activation of Schwann cells and mechanical activation of the same afferent during the ramp phase. RAMs recorded from Sox10-ChR2 mice respond faster to light stimulation than to ramp indentation applied at $15 \mathrm{~mm} / \mathrm{s}$ via piezo actuator (unpaired t test, $P=0.007$ ). (D) Example of spiking from RAMs exposed to blue light 
compared to a mechanical stimulus recorded from glabrous or hairy skin. Mean RAM spiking activity plotted in $1 \mathrm{sec}$ bins from Sox10-ChR2 mice during $10 \mathrm{sec}$ of blue light or mechanical stimulation from glabrous (E) or hairy skin(F). (G) Mechanoreceptor spiking rates rates in response to $20 \mathrm{~Hz}$ vibration stimulus before and after optogenetic inhibition of Schwann cells. Top, RAM representative trace; Bottom, the same unit 10 minutes after yellow light exposure. (H) An increase in the force necessary to evoke the first action potential was observed in RAMs recorded from Sox10-ArchT mice (Two-way ANOVA, $\mathrm{P}=$ 0.0383, Bonferroni's multiple comparisons test). (I) the following frequency decreased after yellow light stimulation in Sox10-ArchT ${ }^{+}$mice but this did not reach statistical significance (two-way ANOVA, $\mathrm{P}=$ 0.047 , Bonferroni's multiple comparisons test).

We used light-induced silencing to ask if Sox $10^{+}$Schwann cells contribute to the coding of vibrotactile stimuli. In Sox10-ArchT and control Sox10-Cre mice we evaluated RAM sensitivity using a $20 \mathrm{~Hz}$ sinusoidal stimulus with a linearly increasing amplitude (Fig. $3 G)$. We measured the force amplitude for the first spike as well as frequency following (where 1.0 denotes a spike evoked by every sinusoid) before and ten minutes after cyclical yellow light was focused on the receptive field. In Sox10-ArchT mice, 9/20 RAMs showed a 3-fold elevation in mean mechanical threshold immediately after the end of the light stimulation compared to control values (Fig. 3G,H, Extended Data Fig. $5 \mathrm{~A}-\mathrm{C}$ ) and this was statistically significant (Two-way ANOVA, $\mathrm{P}<0.05$, Bonferroni's multiple comparison test). The mean mechanical thresholds of RAMs did not change in control Sox10-Cre mice (Fig 3G,H, Extended Data Fig. 5A-C). The number of sinusoid evoked spikes from RAMs in control Sox10-Cre mice remained unchanged after yellow light exposure, but in Sox10-ArchT mice decreased to half of control values, but this effect did not reach statistical significance (Fig. 3H, Extended Data Fig. 2D,E,F). SAMs are not associated with $\mathrm{SOX} 10^{+}$Schwann cells and when these receptors were exposed to yellow light we observed no consistent increase in mechanical threshold or number of evoked spikes per mechanical stimulus (data not shown). Our data thus support the idea that SOX $10^{+}$Schwann cells within the Meissner corpuscle contribute substantially to the transduction of fine touch. 
A

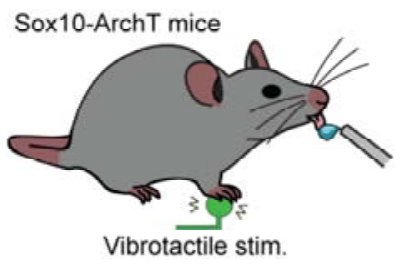

D

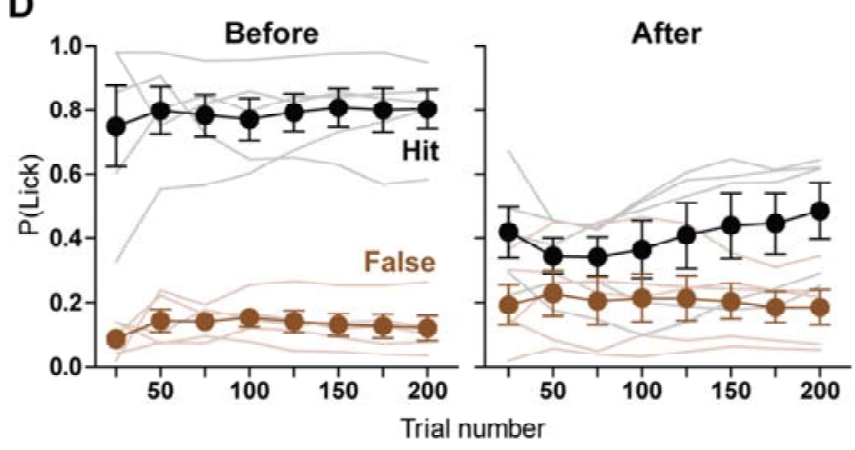

F

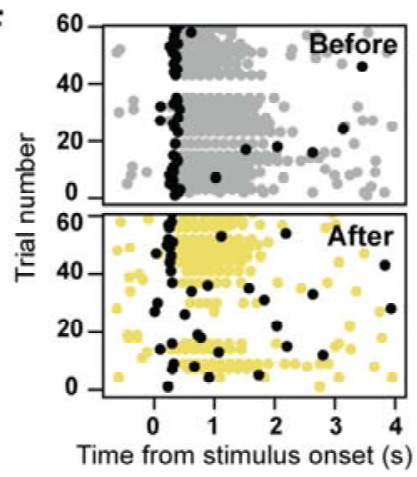

B

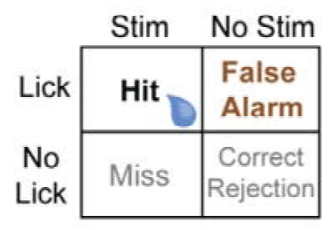

G

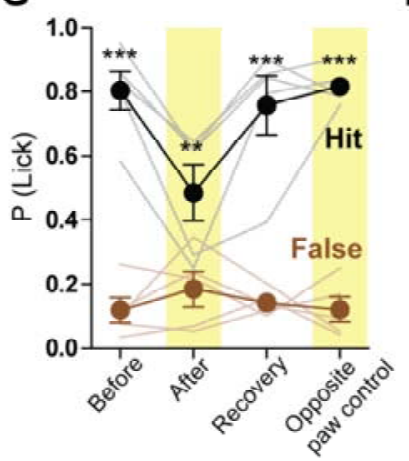

C

E
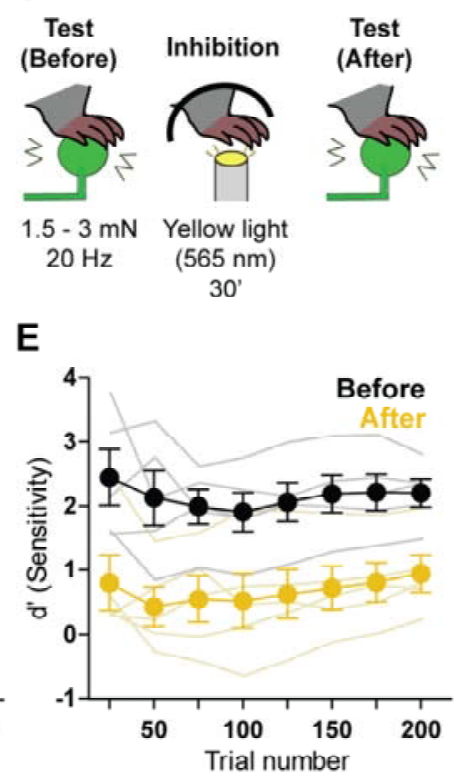

H

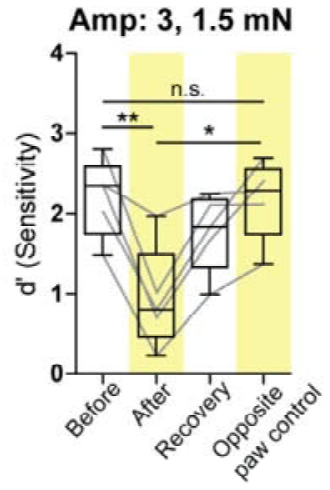

Fig 4. Acute inhibition of vibrotactile perception upon optogenetic inhibition of Sox10+ cells. (A) Cartoon showing behavioral setup with right forepaw placed on a vibrotactile stimulator. (B) Structure of the Go/No Go behavioral task. During stimulus trials, mouse licks were rewarded and classified as "hits". During no stimulus trials, licks were recorded as "false alarms". The proportion of hits and false alarms were later compared to assess performance. (C) Mice reported vibrotactile stimuli of $20 \mathrm{~Hz}$ of frequency and 1.5 or $3 \mathrm{mN}$ of amplitude (for mice with performance lower than $\mathrm{d}<1.5$ when reporting $1.5 \mathrm{mN}, 3 \mathrm{mN}$ were chosen). Mice that reached a good performance $(\mathrm{d}>1.5)$, had their forepaw exposed to yellow light the next day $(565 \mathrm{~nm}, 30$ ') with the same protocol used in skin-nerve recordings. Immediately after the light exposure, their sensitivity to the same vibrotactile amplitude was again tested. (D) Hit and false alarm rates over trials for Sox10-ArchT mice, reporting vibrotactile stimuli on the session before inhibition (left) and after the inhibition (right) $(n=5)$. (E) Sensitivity (d') comparison over trials, corresponding to the hit and false alarm data from before and after the inhibition shown in (D) $(n=5)$. (F) Raster plot of the licks of an example mouse during vibrotactile detection task, before (top) and after (bottom) the optogenetic inhibition. First lick in each trial is shown in black. (G) Session average hit and false alarm rates of Sox10-ArchT mice on different behavior sessions. Statistically significant differences between hits and false alarms were found on the sessions "before", "recovery" and "opposite paw control" $(p<0.001$, Two-way ANOVA with Bonferroni post-hoc), as well as "after" $(p<0.01)(n=5)$. (H) Session average 
sensitivity (d') values of Sox-10-ArchT mice when reporting the vibrotactile stimulus. The sensitivity was lower after the optogenetic inhibition $(p=0.0067)$ than on the session before. Moreover, the sensitivity was also smaller after inhibiting the vibrotactile-sensing paw than when inhibiting the opposite, nonstimulated paw $(p=0.0111$, paired t tests $)(n=5)$.

Meissner corpuscle RAMs are the main afferents required for the perception of tiny skin vibrations ${ }^{14}$. We adapted a goal-directed tactile perception task ${ }^{14}$ and trained waterrestricted and head-restrained Sox10-ArchT mice to report a $20 \mathrm{~Hz}$ sinusoidal stimulus delivered to the forepaw glabrous skin (Fig 4A-C). After training, mice correctly reported detection of the stimulus by licking within a time window of $400 \mathrm{~ms}$, the equivalent of 4 sinusoids of the $20 \mathrm{~Hz}$ stimulus. The probability of a trained mouse correctly reporting stimulus intensities of 1.5 or $3.0 \mathrm{mN}$ was around $80 \% \mathrm{P}$ (lick)=0.8 (Fig. 4D). The next day we exposed the trained or contralateral forepaw to 30 minutes of yellow light (Same duty cycle and intensity as used for recordings above) and retested the mice in the perceptual task immediately after exposure. For the lowest amplitude stimuli used (1.5 or $3.0 \mathrm{mN}$ ), mice exposed to yellow light showed a reduction in their ability to correctly identify the stimulus (Fig 4D). To compare the performance of mice in the detection task we calculated the sensitivity index ( $d$ '; Methods) and found that d' decreased after yellow light exposure (Fig 4E). Many of the correct first lick latencies before yellow light were less than $200 \mathrm{~ms}$ indicating that the mice had perceived the stimulus following only two sinusoids or less (Fig 4F, Extended Data Fig. 6A-C). First lick latencies increased slightly after the yellow light, but this did not reach statistical significance (Extended Data Fig. 6). However, there was a clear tendency for lick latencies to decrease as the trial number increased (Fig. 4F, Extended Data Fig. 6), which might reflect Meissner resident Schwann cell recovery from inhibition. Testing on the next day showed that the mice had recovered their perceptual performance back to control levels (Fig 4G,H). Importantly, mice exposed to yellow light on the opposite forepaw showed no perceptual deficit in the same task, a control for general exposure to yellow light (Fig. 4G,H). These data indicate that Meissner resident sensory Schwann cell are essential for the mice to perceive vibrotactile stimuli relevant for texture discrimination.

Sox $10^{+}$Schwann cells form morphologically and functionally diverse glio-neural endorgans necessary not only for normal mechanical nociception, but also for touch perception. Tight electrical coupling between sensory Schwann cells in Meissner's 
corpuscles as well at least some hair follicles innervated by RAMs ensures that mechanoelectrical transduction in the Schwann cell contributes directly to sensory outflow from the skin (Fig. 3). Light manipulation of Schwann cells sometimes failed to modulate mechanosensitivity, however this could be due to the genetic approach in which the probably no more than $80 \%$ of the Sox $10^{+}$cells would express ChR2 or ArchT. Rapidly-adapting mechanoreceptors convey information about surface texture that can be acted upon in less than $50 \mathrm{~ms}^{24}$, consistent with our finding that blue light activation of Meissner's Schwann cells initiated action potentials faster than the mechanical stimulus. Similarly, mechanonociceptors required for fast mechanical pain $1,25,26$ often showed shorter latencies to light stimulation of nociceptor Schwann cells than to mechanical stimuli (Fig. 2). Despite functional diversity of sensory Schwann cells they possess one common feature which is their selective involvement in the transduction of mechanical stimuli, a feature that appears to be evolutionarily conserved 27 . Thus, we show that polymodal nociceptors require nociceptor Schwann cells for their mechanosensitivity, but not thermosensitivity. Accordingly, polymodality has been compartmentalized between the neuronal nociceptor membrane (thermal transduction) and the nociceptive Schwann cell (mechanotransduction). Our data show that mechanosensation in animals is as much dependent on sensory Schwann cells in the skin as it is on the intrinsic properties of sensory neuron membranes. These results necessitate a major realignment of somatosensory research away from the primary afferent neuron towards specialized glio-neural end-organs in the skin. Understanding the molecular diversity, regulation and plasticity of these functionally distinct glio-neural end-organs will be critical to learning how to treat touch and pain disorders.

\section{Materials and Methods}

Mouse strains

All animal work was permitted by the Ethical Committee on Animal Experiments (Stockholm North committee). Mice of both sexes and from mixed background were 30 used in this study. Animals were kept in cages in groups, with food and water ad libitum, under $12 \mathrm{~h}$ light-dark cycle conditions. Sox $10^{\text {CreERT2 }}$ mouse strains have been previously 
described ${ }^{7}$. Sox2 ${ }^{\text {CreERT2 }}$ (stock number 017593), Rosa26R ${ }^{\text {tdTomato }}$ (stock number 007914), Rosa26R ${ }^{\text {ChR2-EYFP }}$ (stock number 012569) and Rosa26R ${ }^{\text {ArchT-EGFP }}$ (stock number 021188 ) were ordered from The Jackson Laboratory. Sox $10^{\text {CreERT2 }}$ and Sox $2^{\text {CreERT2 }}$ mice were crossed to R26R ${ }^{\text {TOM }}$ mice for histological and Schwann cell isolation experiments and to $R 26 R^{\mathrm{ChR} 2}$ and $\mathrm{R} 26 \mathrm{R}^{\mathrm{ArchT}}$ for functional experiments.

Tamoxifen (Sigma, T5648) was dissolved in corn oil (Sigma, 8267) at a concentration of $20 \mathrm{mg} / \mathrm{ml}$ and delivered by intra peritoneal (i.p.) injection to adult mice or pups (P10).

\section{$\underline{\text { Tissue preparation }}$}

Adult mice were sacrificed with isoflurane overdose and hindpaws were then collected and fixed in PFA for $24 \mathrm{~h}$ at $4^{\circ} \mathrm{C}$, washed 3 times with PBS and cryoprotected by incubating at $4^{\circ} \mathrm{C}$ in $30 \%$ sucrose in PBS for $24 \mathrm{~h}$. Plantar skin of each paw was then dissected out, embedded in OCT compound (Tissue-Tek) and frozen at $-20^{\circ} \mathrm{C}$. Tissue samples were sectioned at $14 \square \mathrm{m}$ thickness and conserved at $-20^{\circ} \mathrm{C}$ until further use.

\section{Immunohistochemistry}

Thawed sections were air dried for one hour at room temperature (RT). Sections were then washed in PBS and incubated in blocking solution (5\% normal donkey serum (NDS, Jackson Immuno Research, \#017-000-121), 2\% Bovine Serum Albumin (BSA, Sigma, \#A7906), $0.3 \%$ Triton $\mathrm{X}-100$ in PBS) for $1 \mathrm{~h}$ before applying primary antibodies overnight at $4^{\circ} \mathrm{C}$. The following primary antibody (diluted in the blocking solution) was used: rabbit anti-PGP9.5 (1:400, Thermo Fisher Scientific, \#PA5-29012). For detection of the primary antibodies, secondary antibodies raised in donkey and conjugated with Alexa-488 fluorophore was used (1:1000, Molecular Probes, Thermo Fisher Scientific) for $1 \mathrm{~h}$ at RT. DAPI staining ( $1 \mathrm{mg} / \mathrm{ml}$, Thermo Fisher Scientific, \#D1306) was performed as the same time as secondary antibodies. Sections were then washed 3 times with PBS and mounted using fluorescent mounting medium for imaging (Dako, \#S3023). Images were acquired using Zeiss LSM700 confocal microscope equipped with 40x objective. Images were acquired in the Ism format and processed with ImageJ. Representative images are projections of Z-stacks taken at $1 \square \mathrm{m}$ intervals. 


\section{Terminal Schwann cell dissociation and culture}

Briefly, terminal Schwann cells were obtained from glabrous skin of Sox10-TOM or Sox10-ChR2 P14 pups. Pups were sacrificed with isoflurane overdose; paws were quickly collected in ice cold HBSS medium (Thermo Fisher Scientific, \#14170112) containing $100 \mathrm{U} / \mathrm{ml}$ penicillin, $100 \mathrm{ug} / \mathrm{ml}$ streptomycin (supplied as a mix, Thermo Fisher Scientific, \#15140122). Plantar skin was then dissected out from each paw, and after removal of nerves and other tissues, skin was incubated in fresh HBSS containing $4 \mathrm{mg} / \mathrm{ml}$ of collagenase/dispase (Sigma-Aldrich, cat.11097113001) for $25 \mathrm{~min}$ at $37^{\circ} \mathrm{C}$. Epidermis was then removed and the dermis, after careful removal of footpads, was cut in small pieces and incubated with collagenase/elastase (Worthington. Cat. LK002066) $4 \mathrm{mg} / \mathrm{ml}$ in HBSS for $40 \mathrm{~min}$ at $37^{\circ} \mathrm{C}$. DNAse I was added (Worthington. Cat. LK003170) to a final concentration of $1 \mathrm{mg} / \mathrm{ml}$ before mechanical dissociation with fire polished Pasteur pipettes coated previously with $1 \%$ BSA in PBS. The cell suspension was slowly filtered through $40 \square \mathrm{m}$-pore size cell strainer and centrifuged at $300 \mathrm{~g}$ for $6 \mathrm{~min}$. The pellet was re-suspended in Schwann cell medium (DMEM with D-valine (Miclev, \#AL251) supplemented with 2mM glutamine (Thermo Fisher Scientific, \#23030081), 10\% Fetal Bovine Serum (Sigma, \#2442), 1\% N2 (Life Technologies, \#17502001), 100 $\mathrm{U} / \mathrm{ml}$ penicillin, $100 \mu \mathrm{g} / \mathrm{ml}$ streptomycin, $5 \mu \mathrm{M}$ forskolin (Sigma \#F6886) and $20 \square \mathrm{g} / \mathrm{ml}$ bovine pituitary extract (Sigma, \#P1476). Cells were plated on coverslips coated with poly-L-lysine (Sigma, \#P4707) for $2 \mathrm{~h}$ at $37^{\circ} \mathrm{C}$ and then with laminin (Sigma, \#L2020) for 30 min at $37^{\circ} \mathrm{C}$. Cells were cultured in humidified $5 \% \mathrm{CO}_{2} / 95 \%$ air atmosphere. Cultured cells were used for experiments between days 2 and 4 days in vitro.

Whole-cell electrophysiology

Whole-cell patch-clamp voltage clamp recordings were performed on Sox10 ${ }^{\mathrm{TOM}}$ (at DIV

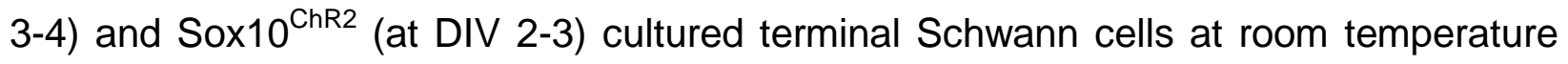
$\left(20-24^{\circ} \mathrm{C}\right)$. Recordings from fluorescent cells were performed using Multiclamp 700B amplifier (Molecular Devices) and analyzed off-line in Clampfit software (Molecular Devices). Patch pipettes with a tip resistance of $2-3 \mathrm{M} \Omega$ were filled with intracellular solution (in mM):105 K-gluconate, $30 \mathrm{KCl}, 10 \mathrm{Na}$-Phosphocreatine, $10 \mathrm{HEPES}, 4 \mathrm{Mg}$ ATP, $0.3 \mathrm{Na}-\mathrm{GTP}$ and $\mathrm{pH}$ adjusted to 7.3 with $\mathrm{KOH}$. The extracellular solution contained 
(in mM): $125 \mathrm{NaCl}, 2.5 \mathrm{KCl}, 25 \mathrm{NaHCO}, 1.25 \mathrm{NaH} 2 \mathrm{PO} 4,1 \mathrm{MgCl} 2,2 \mathrm{CaCl}$, 20 glucose and 20 HEPES. Cells were clamped to a holding potential of $-40 \mathrm{mV}$ and stimulated with a series of mechanical stimuli with probes (tip diameter 2-3 $\mu \mathrm{m}$ ) that were custommade with patch pipettes heated for $10 \mathrm{~s}$ with a microforge (Narishige MF-90). Mechanical probe was manipulated by a piezo-driven micromanipulator (Nanomotor MM3A; Kleindiek Nanotechnik). Movements of the mechanical probe were executed in the in/out axis of the device (axis C). A voltage divider box (MM3-LS trigger, Kleindiek Nanotechnik) was connected that provided analog voltage output signal corresponding to the piezo signals. Depending on the movement of piezo micromanipulator, the voltage signal was registered as small pulse or just a change in a DC voltage. For optogenetic stimulation, see section "Excitatory optogenetic"

\section{Extracellular recording from tibial nerve}

15 Electrophysiological recordings from cutaneous sensory fibers of the tibial nerve were made using an ex vivo skin nerve preparation following the method described previously ${ }^{7,18}$. Briefly, the animal was sacrificed by cervical dislocation and the hair of the limb was shaved off. The glabrous skin from the hind paw was removed along with the tibial nerve dissected up to the hip and cut. The glabrous skin along with the tibial nerve still attached to the hindpaw was transferred to a bath chamber which was constantly perfused with warm $\left(32^{\circ} \mathrm{C}\right)$ oxygen-saturated interstitial fluid. The remaining bones, muscle and ligament tissue were gently removed as much as possible, allowing the glabrous skin and tibial nerve preparation to last at least 6 hours of recording in healthy a stable condition in an outside-out configuration. The tibial nerve was passed through a narrow channel to an adjacent recording chamber filled with mineral oil.

Single-unit recordings were made as previously described ${ }^{7,18}$. Fine forceps were used to remove the perineurium and fine nerve bundles were teased and placed on a platinum wire recording electrode. Mechanical sensitive units were first located using blunt stimuli applied with a glass rod. The spike pattern and the sensitivity to stimulus velocity were used to classify the unit as previously described ${ }^{7,18}$. Raw data were recorded using an analog output from a Neurolog amplifier, filtered and digitized using a Powerlab 4/30 system and Labchart 8 software with the spike-histogram extension 
(ADInstruments Ltd., Dunedin, New Zealand). All mechanical responses analyzed were corrected for the latency delay between the electrical stimulus and the arrival of the action potential at the electrode. The conduction velocity (CV) was measuring the formula $\mathrm{CV}=$ distance/time delay, in which $\mathrm{CVs}>10 \mathrm{~ms}^{-1}$ were classified as RAMs or SAMs $\left(A \beta,<10 \mathrm{~ms}^{-1}\right.$ as $A \delta$ and $<1 \mathrm{~ms}^{-1}$ as $C$-fibers.

Mechanical Stimulation

Mechanical stimulation of the receptor field of the recorded fibers was performed using a piezo actuator (Physik Instrumente, Germany, P-602.508) connected to a force measurement device (Kleindiek Nanotechnik, Reutlingen, Germany, PL-FMS-LS). Different mechanical stimulation protocols were used to identify and characterize the sensory afferents. Mechanoreceptors were tested with a vibrating stimulus with increasing amplitude and $20 \mathrm{~Hz}$ frequency. The force needed to evoke the first action potential was measured. Additionally, a ramp and hold step was used with Constant force $(100 \mathrm{mN})$ and repeated with varying probe movement velocity $(0.075,0.15,0.45$, 1.5 and $15 \mathrm{~mm} \mathrm{~s}^{-1}$ ). Only the firing activity evoked during the dynamic phase were analyzed. SAM mechanoreceptors and nociceptors were tested with a mechanical stimulus with a constant ramp (1.5-2 $\left.\mathrm{mN} \mathrm{ms}^{-1}\right)$ and increasing force amplitude, spikes evoked during the static phase were analyzed.

Thermal stimulation

20 Thermal stimulation was carried out in two ways. First, a qualitative classification of Cfiber nociceptors was made applying cold and hot SIF buffer directly to the receptive field of the terminal ending which was isolated by metal ring. Cold buffer was kept on ice at $4^{\circ} \mathrm{C}$ and reach approximately $10^{\circ} \mathrm{C}$ at stimulation. Hot buffer was kept in a shaker incubator at $80^{\circ} \mathrm{C}$ and skin temperature reached approximately $50^{\circ} \mathrm{C}$ during stimulation. Thereafter, a custom designed thermostimulator connected to a thermocouple and Peltier that could be placed in direct contact with the skin was used. Two sequential temperature ramps were applied to test the thermoreceptors sensitivity. First, a cold ramp starting at $32^{\circ} \mathrm{C}$ (the skin basal temperature) and decreasing in 2 degrees per second rate until reaching $12^{\circ} \mathrm{C}$ and coming back to $32^{\circ} \mathrm{C}$ as fast as possible. Thereafter, a heat ramp was applied starting from $32^{\circ} \mathrm{C}$ with an increasing temperature of 2 degrees per second until reaching $52^{\circ} \mathrm{C}$ and coming back to $32^{\circ} \mathrm{C}$ as fast as 
possible. A gap of 30 seconds between the two thermal ramp stimulation was used for sensory afferents to recover.

The piezo actuator, thermostimulator, and optogenetic lamp for blue and yellow light were connected to a micromanipulator assisted in the positioning and a Magnetic stand.

Excitatory optogenetic

Cultured Schwann cells or receptive fields in the skin-nerve preparation were stimulated with blue light (470nm, $5 \mathrm{sec}$ on for patch-clamp or $10 \mathrm{sec}$ on for skin-nerve preparation) applied through a flexible optical fiber bundle with $90^{\circ}$ angle (consequently) with increasing light intensity from $0.5,2.6,3.9$ and $4.3 \mathrm{~mW} / \mathrm{mm}^{2}$.

\section{Inhibitory optogenetics}

We used yellow light $(575 \mathrm{~nm}, 10 \mathrm{~min})$ stimulation for the skin-nerve preparation. The light was applied to the receptive field in plantar surface of the hind paw with a $5 \mathrm{~s}$ ON, 1 s OFF pulsing frequency. The light intensity was $0.5 \mathrm{~mW} / \mathrm{mm}^{2}$.

\section{Head implanting of mice for behavioral training}

Mice were anesthetized with isoflurane (3-4\% initiation, 1.5-2\% maintenance in 02$)$ and had a subcutaneous injection of Metamizol (200 mg per $\mathrm{kg}$ of body weight). The temperature of the animals was monitored at all times and kept at 37oC using a heating pad. A light metal support was implanted onto the skull with glue (UHU dent) and dental cement (Paladur). Mice recovered at their home cage and had Metamizol in the drinking water $(200 \mathrm{mg} / \mathrm{mL})$ for $1-3$ days.

\section{Mouse vibrotactile Go/No Go detection task}

Head implanted mice underwent habituation to the behavioral setup at several times for 4 days with increasing head restraint periods (5-60 minutes). The right forepaw was tethered with medical tape to a glass surface with a small hole, through which the vibrotactile stimulator could contact the center of the forepaw. The vibrotactile stimulator (smooth plastic cylinder $\sim 2 \mathrm{~mm}$ diameter, driven by Dual-Mode Lever System 300C, Aurora Scientific) therefore touched the right forepaw glabrous skin. During habituation, the animals were occasionally rewarded with condensed milk droplets to reduce stress. 
Next, the animals were water restricted and underwent two pairing sessions (3060mins) where vibrotactile stimuli were presented together with water rewards $(4-7 \mu \mathrm{l})$ coming from a lick spout, in order to form an association between stimulus and reward. After the pairing, mice were trained on consecutive days to lick the water spout in response to a vibrotactile stimuli (1 s long, increases in force of up to $15-20 \mathrm{mN}$ at 20 $\mathrm{Hz}$, starting from a constant baseline of $9 \mathrm{mN}$ ), with water rewards being given when the mice licked during the stimulus presentation. Performance was assessed by comparing the correctly reported stimulations (hits) with spontaneous licking occurring during catch trials (no-stimulus time windows of the same length as stimulus trials) (false alarms). Mice that reached a d'>1.5 (see analysis of behavior) were then trained with shorter stimuli of lower amplitudes (0.4 s long, interleaved vibrotactile stimuli of $20 \mathrm{~Hz}$ and 1.5 or $3 \mathrm{mN}$ amplitude from a $9 \mathrm{mN}$ baseline) until they reached d'>1.5 in these conditions. Each training session on low amplitudes lasted for 200 trials, with equal proportions of each amplitude and catch trials.

To inhibit Sox10-ArchT cells before behavioral testing, we temporarily replaced the vibrotactile stimulator with a yellow LED light (Thorlabs). The LED light illuminated the paw from a distance of $\sim 3 \mathrm{~cm}$ below the glabrous skin. The equipment and light parameters were the same as in ex-vivo recordings, with the only difference being the duration of light stimulation (30 mins). The increased stimulation time in behavior aimed to suppress Sox10+ cell activity for a longer time, since a behavioral session lasted for 40-60 minutes. The whole paw and light stimulator were covered with optical blackout cloth (Thorlabs) in order to prevent the mice from seeing the light, and illuminating any other body region of the mice. To assess whether the observed effect was dependent on the stimulated skin region, we stimulated the untrained, contralateral (left) forepaw and saw no effect.

\section{Analysis of behavior}

Licks of the water spout were measured using a capacitance sensor. The performance during the detection task was assessed by comparing the hit (\% of reported stimulus trials) with false alarm (\% of reported catch trials) rates. Each trial consisted of a prestimulus window of $0.5 \mathrm{~s}$, followed by a stimulus (or catch) window of $0.4 \mathrm{~s}$. Licks after 
this time window were excluded for performance analysis. Trials were delayed by a random interval between 3 and 30s if mice spontaneously licked during a 2 s window before the start of a new trial. All mice had to detect interleaved stimuli of 1.5 and $3 \mathrm{mN}$. Performance data for each mouse was obtained for trials of 1.5 and $3 \mathrm{mN}$ before and after the optogenetic manipulation. Since some mice showed a deficit when reporting both 1.5 and $3 \mathrm{mN}$ while others only showed an effect for $1.5 \mathrm{mN}$, the analysis was carried out on the largest amplitude affected in each mouse. 1/7 mice did not meet the perceptual performance criteria for optogenetic testing, and one further mouse was excluded from analysis because it did not show any effect of optogenetic manipulation most likely because of variability of $\mathrm{ARCH}$ expression during tamoxifen induction.

To compare performance between different mice and training sessions, we used d' (sensitivity index) instead of the \% of correct trials, in order to account for bias in the licking criterion. Sensitivity was calculated with the formula d' $=z(h)-z(f a)$, where $z(h)$ and $z(\mathrm{fa})$ are the normal inverse of the cumulative distribution function of the hit and false alarm rates, respectively.

The $\mathrm{z}$ scores for hit and false alarm rates were calculated with OpenOffice Calc (Apache Software Foundation) using the function NORMINV.

The behavioral training was run with Bpod (Sanworks) and data was collected with custom-written routines in MATLAB (Mathworks). Custom-written MATLAB and Python (Python Software Foundation) scripts were used for analysis.

\section{Statistical tests}

Statistical analyses were carried out with GraphPad Prism 5.0/6.0 and Python. Statistical tests for significance are stated in the text, and include Mann Whitney test, Wilcoxon matched pairs test and Student t test. Asterisks in figures indicate statistical significance: ${ }^{*} \mathrm{p}<0.05,{ }^{* *} \mathrm{p}<0.01,{ }^{* * *} \mathrm{p}<0.001$.

\section{Quantification and Statistics}

In the patch clamp experiments the tau ( $\mathrm{T}$ ) value of activation and inactivation of a current trace was calculated as exponential fit of different phases using Clampfit 10.7 software. To calculate $p$ value and statistical significance unpaired t-test was performed. 
In the skin nerve experiments, raw data were stored and processed using Microsoft Excel. Statistical tests were performed using Prism 8 (GraphPad Software, San Diego, CA, USA). Data were tested for normality. Light-responsive and non-responsive sensory afferents, and light-and mechanical response from the same sensory afferent, were compared using unpaired Student's $t$-tests or multiple comparisons two-way repeatedmeasures analysis of variance (ANOVA) and post-hoc tests performed with Bonferroni's multiple comparisons test. Significance values are reported as: * denotes $P$ value $\leq$ $0.05 ;{ }^{* *}$ denotes $P$ value $\leq 0.005 ;{ }^{* *}$ denotes $P$ value $\leq 0.0005$. All error bars are standard error of the mean (SEM).

\section{References}

1. Lewin, G. R. \& Moshourab, R. Mechanosensation and pain. J. Neurobiol. 61, 30-44 (2004).

2. Yang, Y., Mis, M. A., Estacion, M., Dib-Hajj, S. D. \& Waxman, S. G. NaV1.7 as a Pharmacogenomic Target for Pain: Moving Toward Precision Medicine. Trends Pharmacol Sci 39, 258-275 (2018).

3. Lewin, G. R. William D. Willis, Jr, MD, PhD Memorial Lecture: The evolutionary history of nerve growth factor and nociception. Pain 161, S36-S47 (2020).

4. Murthy, S. E. et al. The mechanosensitive ion channel Piezo2 mediates sensitivity to mechanical pain in mice. Science Translational Medicine 10, eaat9897 (2018).

5. Wetzel, C. et al. A stomatin-domain protein essential for touch sensation in the mouse. Nature 445, 206-209 (2007).

6. Ranade, S. S. et al. Piezo2 is the major transducer of mechanical forces for touch sensation in mice. Nature 516, 121-125 (2014).

7. Wetzel, C. et al. A stomatin-domain protein essential for touch sensation in the mouse. Nature 445, 206-9 (2007). 
8. Poole, K., Herget, R., Lapatsina, L., Ngo, H.-D. \& Lewin, G. R. Tuning Piezo ion channels to detect molecular-scale movements relevant for fine touch. Nat Commun 5, 3520 (2014).

9. Drew, L. J., Wood, J. N. \& Cesare, P. Distinct Mechanosensitive Properties of Capsaicin-Sensitive and -Insensitive Sensory Neurons. J. Neurosci. 22, RC228 (2002).

10. Hu, J. \& Lewin, G. R. Mechanosensitive currents in the neurites of cultured mouse sensory neurones. J. Physiol. (Lond.) 577, 815-828 (2006).

11. Abdo, H. et al. Specialized cutaneous Schwann cells initiate pain sensation. Science (New York, N.Y.) 365, 695-699 (2019).

12. Rinwa, P. et al. Demise of nociceptive Schwann cells causes nerve retraction and pain hyperalgesia. Pain 162, 1816-1827 (2021).

13. Neubarth, N. L. et al. Meissner corpuscles and their spatially intermingled afferents underlie gentle touch perception. Science 368, (2020).

14. Schwaller, F. et al. USH2A is a Meissner's corpuscle protein necessary for normal vibration sensing in mice and humans. Nat Neurosci 24, 74-81 (2021).

15. Perl, E. R. Myelinated afferent fibres innervating the primate skin and their response to noxious stimuli. The Journal of Physiology 197, 593-615 (1968).

16. Paricio-Montesinos, R. et al. The Sensory Coding of Warm Perception. Neuron 106, 830-841.e3 (2020).

17. Milenkovic, N. et al. A somatosensory circuit for cooling perception in mice. Nat. Neurosci. 17, 1560-1566 (2014). 
18. Walcher, J. et al. Specialized mechanoreceptor systems in rodent glabrous skin. The Journal of Physiology 596, 4995-5016 (2018).

19. Johnson, K. O. The roles and functions of cutaneous mechanoreceptors. Current Opinion in Neurobiology 11, 455-461 (2001).

20. Maksimovic, S. et al. Epidermal Merkel cells are mechanosensory cells that tune mammalian touch receptors. Nature (2014) doi:10.1038/nature13250.

21. Woo, S.-H. et al. Piezo2 is required for Merkel-cell mechanotransduction. Nature (2014) doi:10.1038/nature13251.

22. Morrison, K. M., Miesegaes, G. R., Lumpkin, E. A. \& Maricich, S. M. Mammalian Merkel cells are descended from the epidermal lineage. Dev Biol 336, 76-83 (2009).

23. Hoffman, B. U. et al. Merkel Cells Activate Sensory Neural Pathways through Adrenergic Synapses. Neuron (2018) doi:10.1016/j.neuron.2018.10.034.

24. Luna, R., Hernandez, A., Brody, C. D. \& Romo, R. Neural codes for perceptual discrimination in primary somatosensory cortex. Nat Neurosci 8, 1210-9 (2005).

25. Arcourt, A. et al. Touch Receptor-Derived Sensory Information Alleviates Acute Pain Signaling and Fine-Tunes Nociceptive Reflex Coordination. Neuron 93, 179-193 (2017).

26. Nagi, S. S. et al. An ultrafast system for signaling mechanical pain in human skin. Sci Adv 5, eaaw1297 (2019).

27. Nikolaev, Y. A. et al. Lamellar cells in Pacinian and Meissner corpuscles are touch sensors. Sci Adv 6, (2020). 


\section{Acknowledgments:}

This research was funded by the ERC (PainCells 740491 to PE and Sensational Tethers 789128 to GRL), the Swedish MRC (2019-00761 to PE), KAW Scholar and project grant, Wellcome Trust (200183) to PE. RK was supported by a DBT Ramalingaswami Fellowship (BT/HRD/35/02/2006), IBRO Return Home Fellowship and ISN-CAEN Return Home Grant. MDZ was supported by a Brain foundation and Swedish Society for Medical Research (SSMF) post-doc fellowship. We thank members of the Lewin and Ernfors lab for constructive comments on the manuscript.

Author contributions: Conceptualization: G.R.L and P.E.; mouse models/experimental design: J. O-A. and L.C.-E.; nerve recording and formal analysis: J. O-A.; mouse behavior R. P-M and J. F.A.P.; immunohistochemistry: L.C.-E. and M-D. Z.; patch clamp electrophysiology: R. K.; writing (J. O-A., L.C.-E., P.E., and G.R.L) with input from all authors; and supervision and funding: G.R.L and P.E.

Competing interests: Authors declare no competing interests.

Data and materials availability: All data is available in the main text or the supplementary materials. All data, code, and materials used in the analysis must be available in some form to any researcher for purposes of reproducing or extending the analysis. 


\section{Extended Data Figures}

Extended Data Figures 1-6
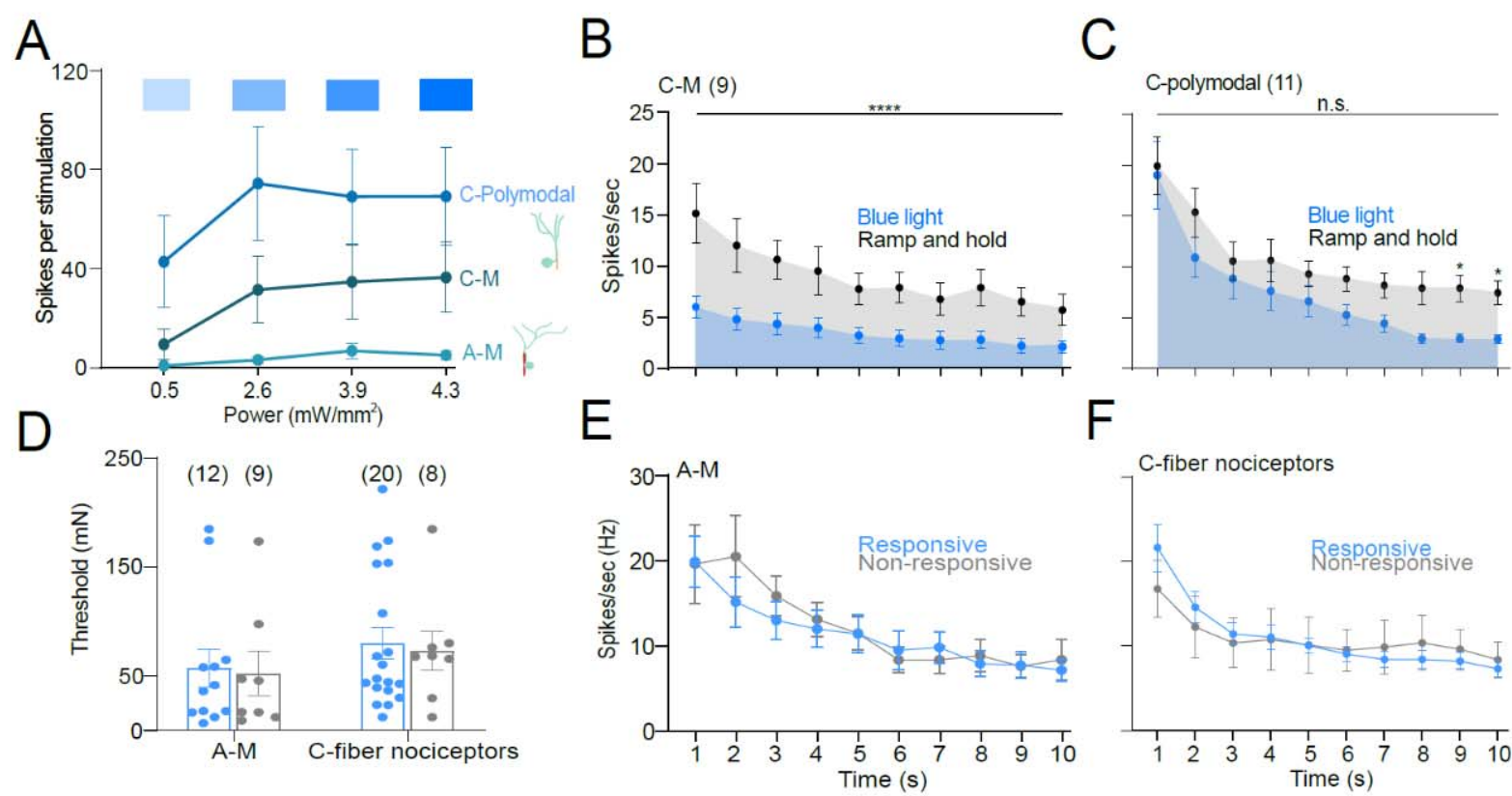

$\mathrm{F}$

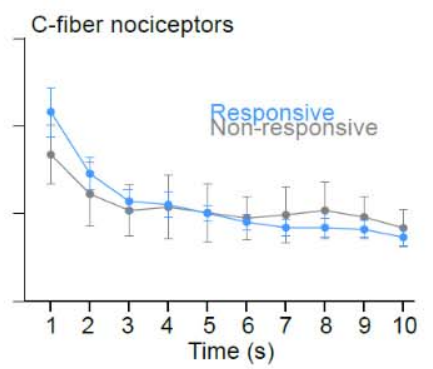

Extended Data Fig. 1. Mechanosensitive properties of light responsive and nonresponsive nociceptors. (A) Action potential firing of nociceptors from Sox10 ChR2 mice to different levels of blue light stimulation (B-C) Mean time course of Cmechanonociceptors (B) and C-fiber polymodal (C) blue light and mechanical activation (1s bins, 10s stimulus $250 \mathrm{mN}$ ). (D) Mechanical threshold comparison of A-fiber nociceptors and C-fiber nociceptors from Sox10-ChR2 mice including all fibers recorded, irrespective of blue light sensitivity. (E-F). A suprathreshold mechanical stimulus $(250 \mathrm{mN})$ evoked firing from blue light responsive and non-responsive A-Ms (E) and C-fiber nociceptors (F) Mean spiking rates of responsive (blue) and nonresponsive (grey) neurons. 
A

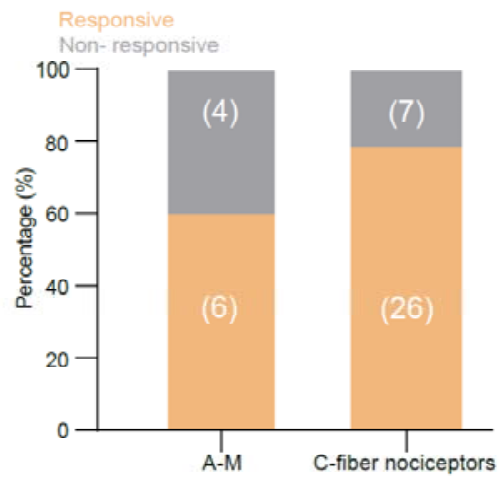

C

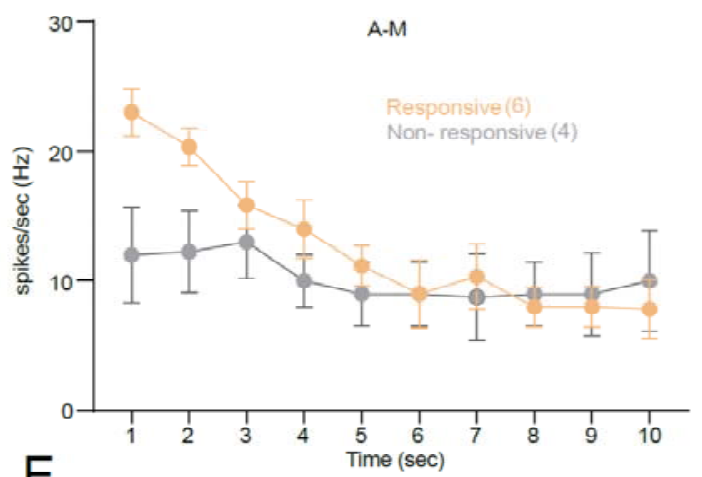

$\mathrm{E}$

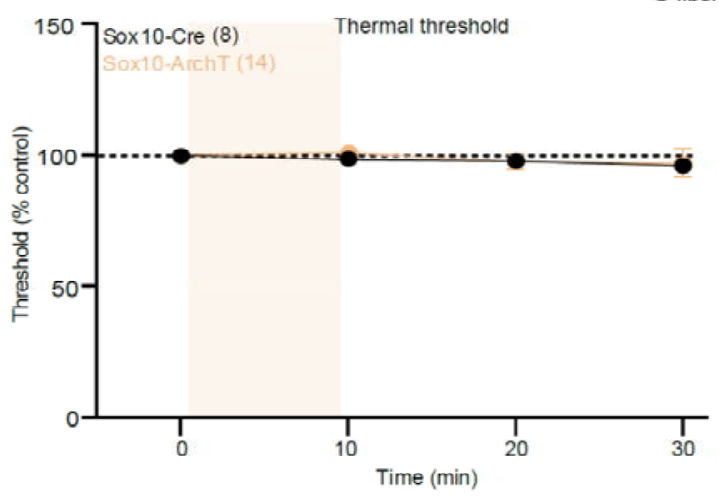

B

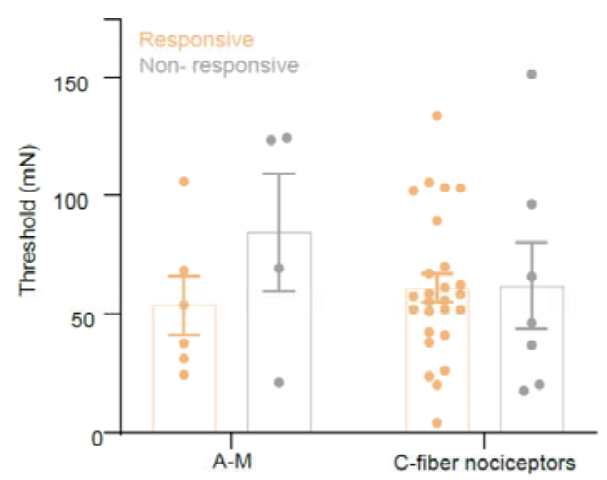

D

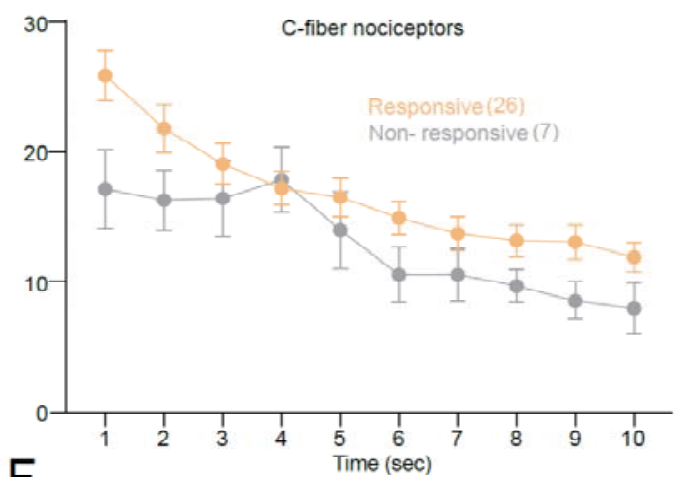

F

C-fiber polymodal

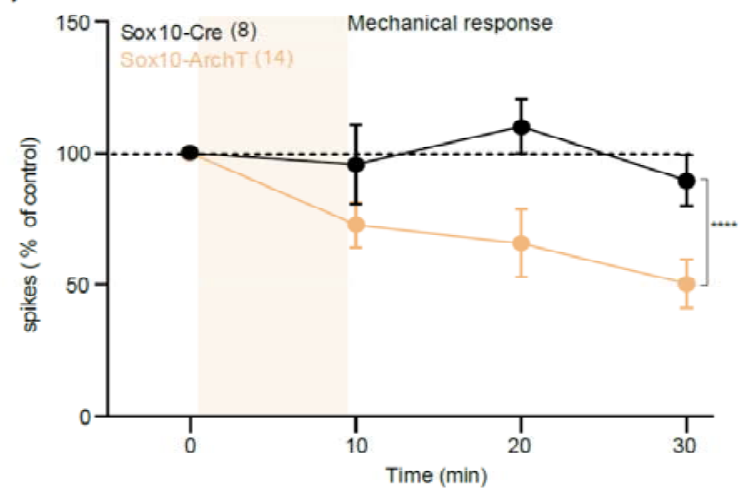

Extended Data Fig. 2. Mechanosensitive properties of yellow light responsive and non-responsive nociceptors. (A) Percentage of A-M and C-fiber mechanonociceptors responsive (yellow) and non-responsive (gray) to yellow light photoinhibition of Sox $10^{+}$ Sensory Schwann cells. (B-D) A- fiber nociceptors and C-mechanonociceptors show similar mechanical thresholds (B) and firing to increasing amplitude ramp-and-hold stimuli irrespective of whether activated by blue light or not(C,D). (E,F) Change in Thermal or mechanically evoked activity from C-polymodal nociceptors to temperature stimulation (E), heating and cooling ramps $2^{\circ} \mathrm{C} / \mathrm{s}$ or mechanical stimuli $(\mathbf{F})$ before and after yellow light in Sox10-ArchT mice. Note that thermal threholds (E) were unchanged although in the same fibers a profound decreases in mechanically evoked activity was observed (F), two-way ANOVA, $P<0.001$, Bonferroni's multiple comparison test. 

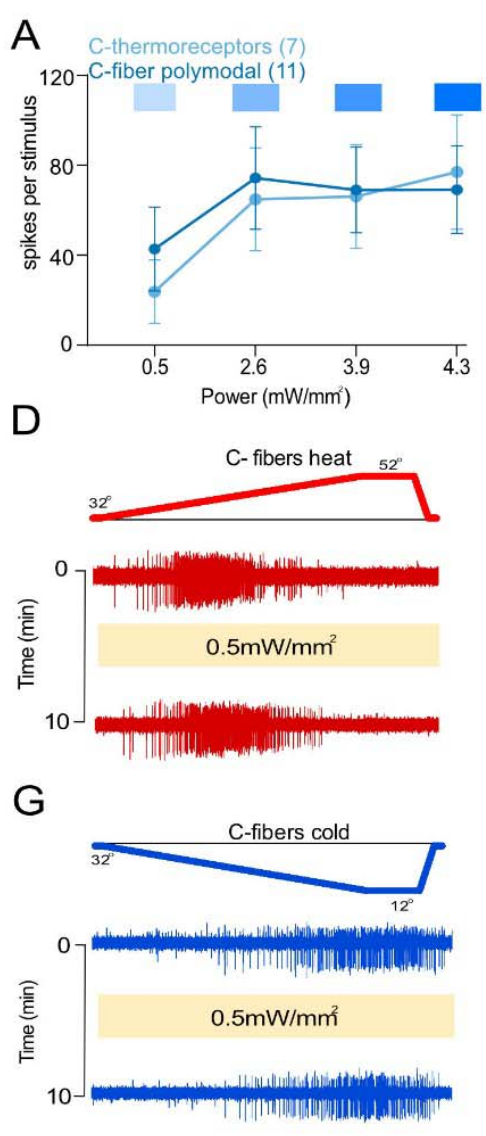
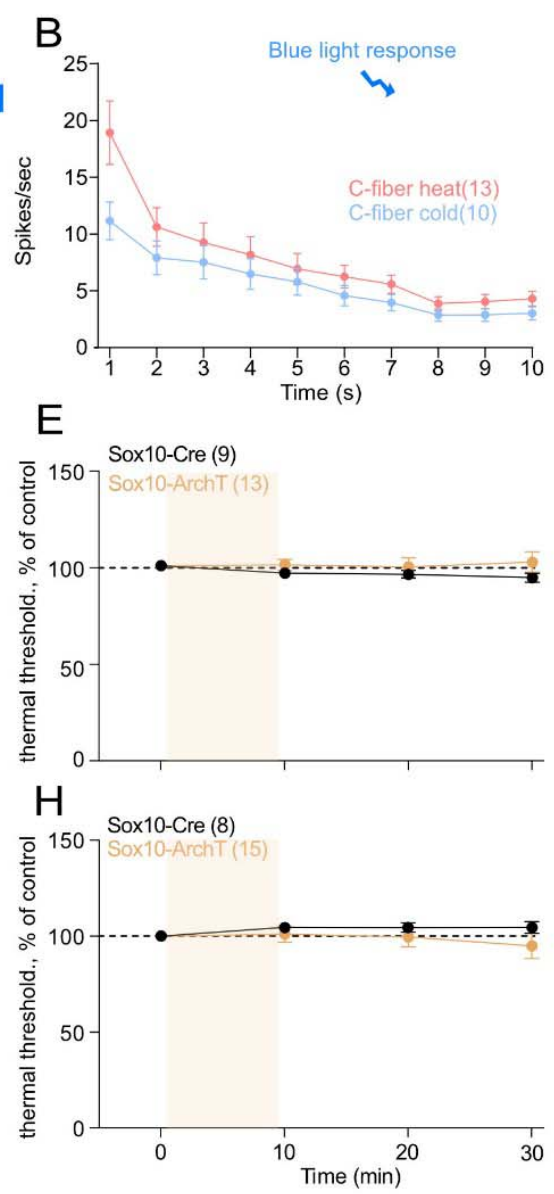

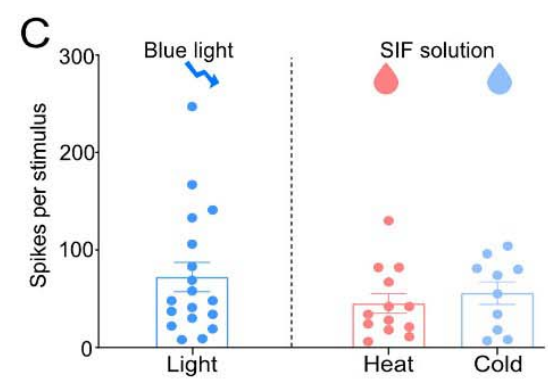

$\mathrm{F}$
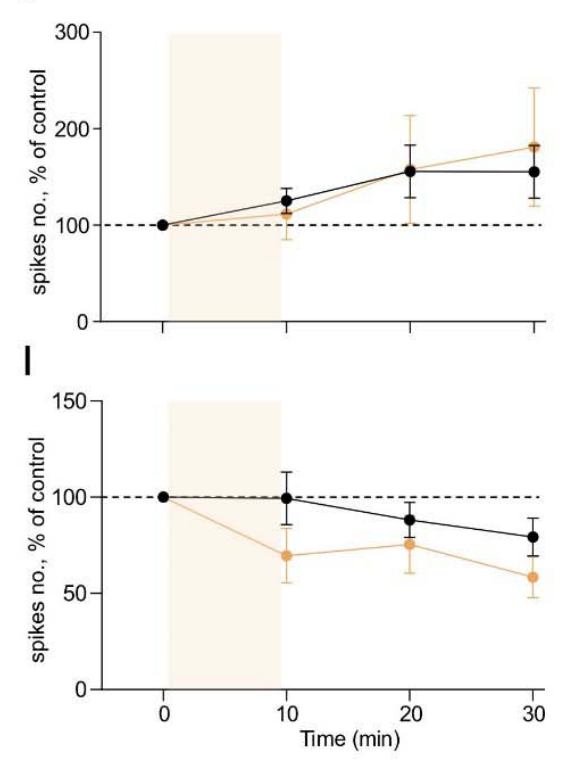

Extended Data Fig. 3. Thermosensitivity of C-fiber afferents was unchanged by optogenetic stimulation of nociceptive Schwann cells (A) Action potential firing of C-polymodal and C-thermoreceptors from Sox10-ChR2 mice to four intensities of blue light stimulation. (B) Mean firing activity (1s bin, 10 bins) to blue light from C-fibers responsive to heat (light red) or cold (light blue). (C) Total number of action potentials evoked by photostimulation or local application of hot/cold SIF to C-fiber receptive fields of heat (light red) or cold (light blue) sensitive C-fibers. (D-F) Representative traces show C-fiber activity to a heat-ramp stimuli before and 10 minutes after yellow light. Cthermoreceptors heat responsive threshold $(\mathbf{E})$ and heat-ramp evoked activity $(\mathbf{F})$, before and after yellow light in Sox10-ArchT mice during 30 minutes of recording (twoway ANOVA, $\mathrm{P}>0.5$, Bonferroni's multiple comparison test). (G-I) Representative traces show C-fiber activity to cold-ramp stimuli before and 10 minutes after yellow light. The threshold temperature for cold activation (E) or the cold ramp evoked activity (F) following yellow light in Sox10-ArchT mice during 30 minutes of recording were unchanged ( $P>0.4$, two-way ANOVA, Bonferroni's multiple comparison test). 


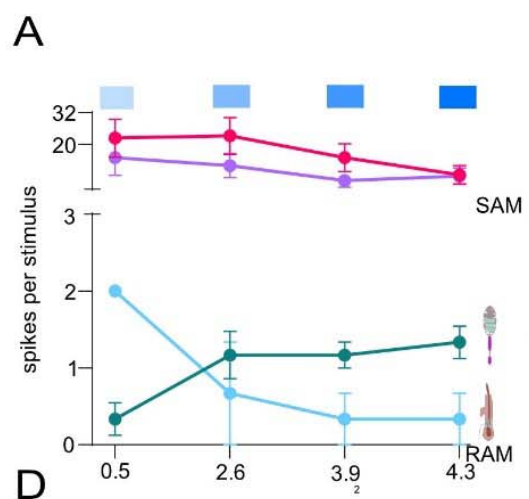

B

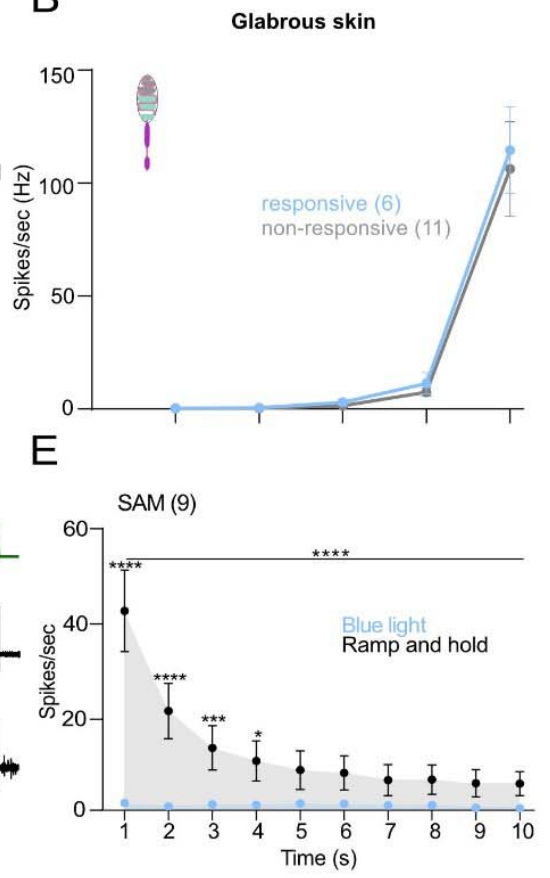

C
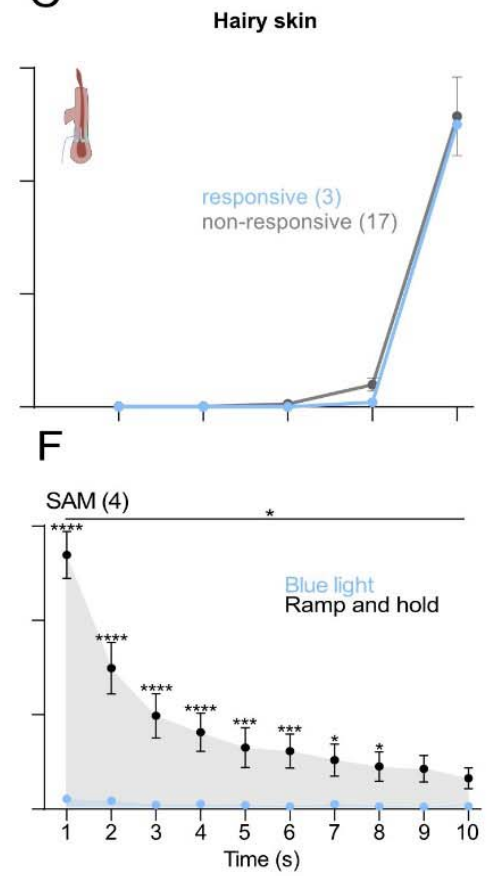

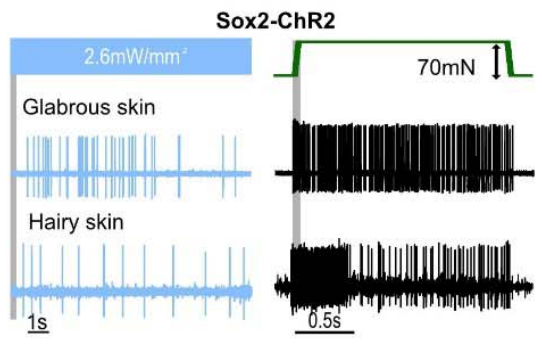

Extended Data Fig. 4 Blue light responsive mechanoreceptors in hairy and glabrous skin. (A) Action potential firing of RAMs in hairy (green) and glabrous (blue) and SAMs in hairy (purple) and glabrous (pink) from Sox10 ChR2 mice to blue light stimulation. (B-C) Firing activity in response to mechanical stimuli with varying rampvelocity of blue light responsive and non-responsive RAMs from Sox10-ChR2 showing similar sensitivities to movement. (D-F) Spiking from SAMs exposed to blue light compared to a mechanical stimulus recorded from glabrous or hairy skin of Sox2-ChR2 mice (D). Mean SAM spiking activity plotted in $1 \mathrm{sec}$ bins from Sox2-ChR2 mice during $10 \mathrm{sec}$ of blue light or mechanical stimulation from glabrous $(\mathbf{E})$ or hairy $\operatorname{skin}(\mathbf{F})$. 
A

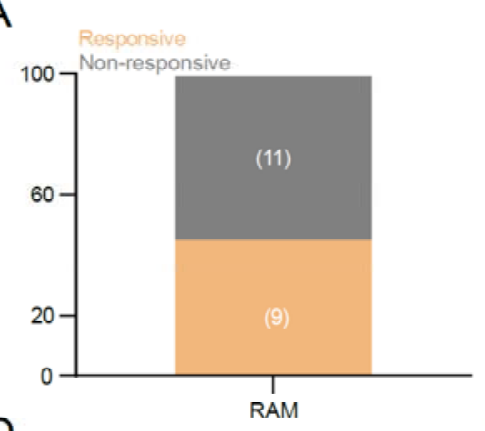

D

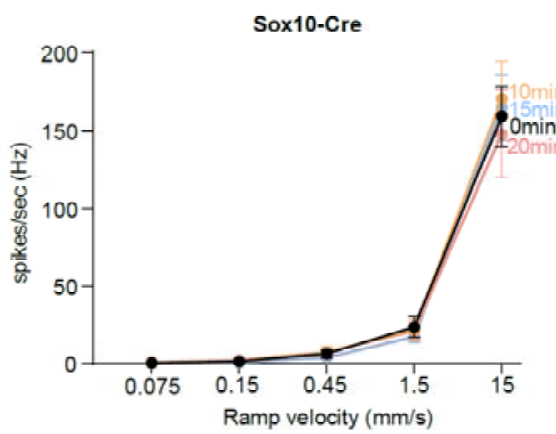

B

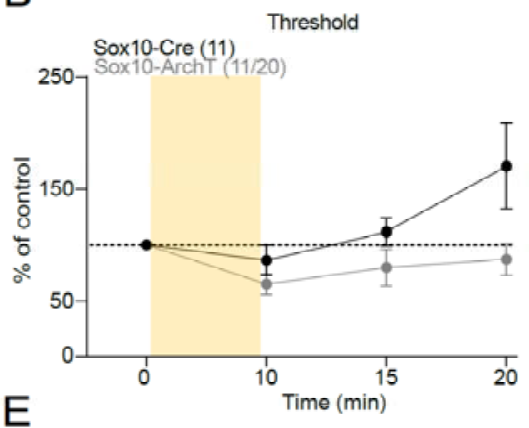

C
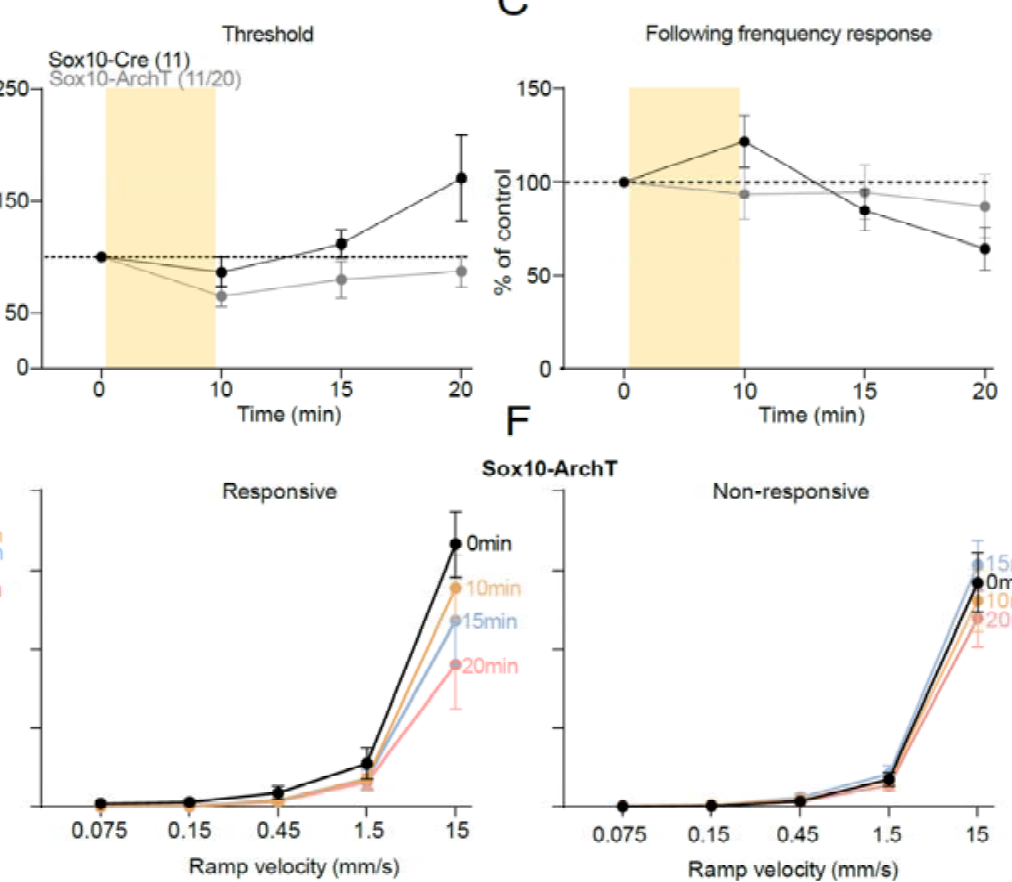

Sox10-ArchT

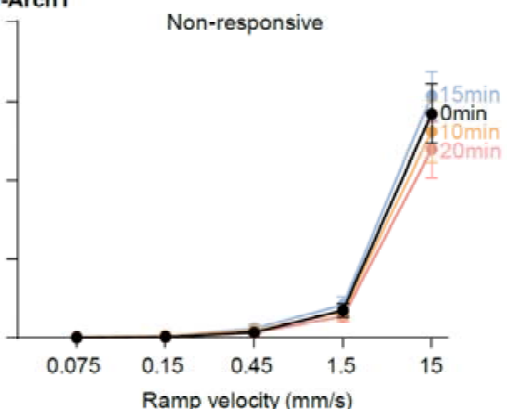

Extended Data Fig. 5 Physiological properties of non-yellow light responsive RAMs. (A) Percentage of RAMs responsive (yellow) and non-responsive (gray) to photoinhibition of Sox $10^{+}$Sensory Schwann cells by yellow light exposure. (B-C) Force threshold necessary to evoke the first action potential was observed in RAMs nonaffected by yellow light exposure recorded from Sox10-ArchT mice, showing no difference compared to RAM recordings from Sox10-Cre control mice. (C) The following frequency from non-affected RAMs before and after yellow light photoinhibition in Sox10-ArchT mice. (D-F) Firing activity in response to mechanical stimuli with increasing ramp-velocity of RAMs from Sox10-Cre compared to RAMs that were responsive or non-responsive to photoinhibition of Sox $10^{+}$Sensory Schwann. Movement detection was decreased in RAMs recorded from responsive neurons from Sox10-ArchT mice although this was not statistically significant. 

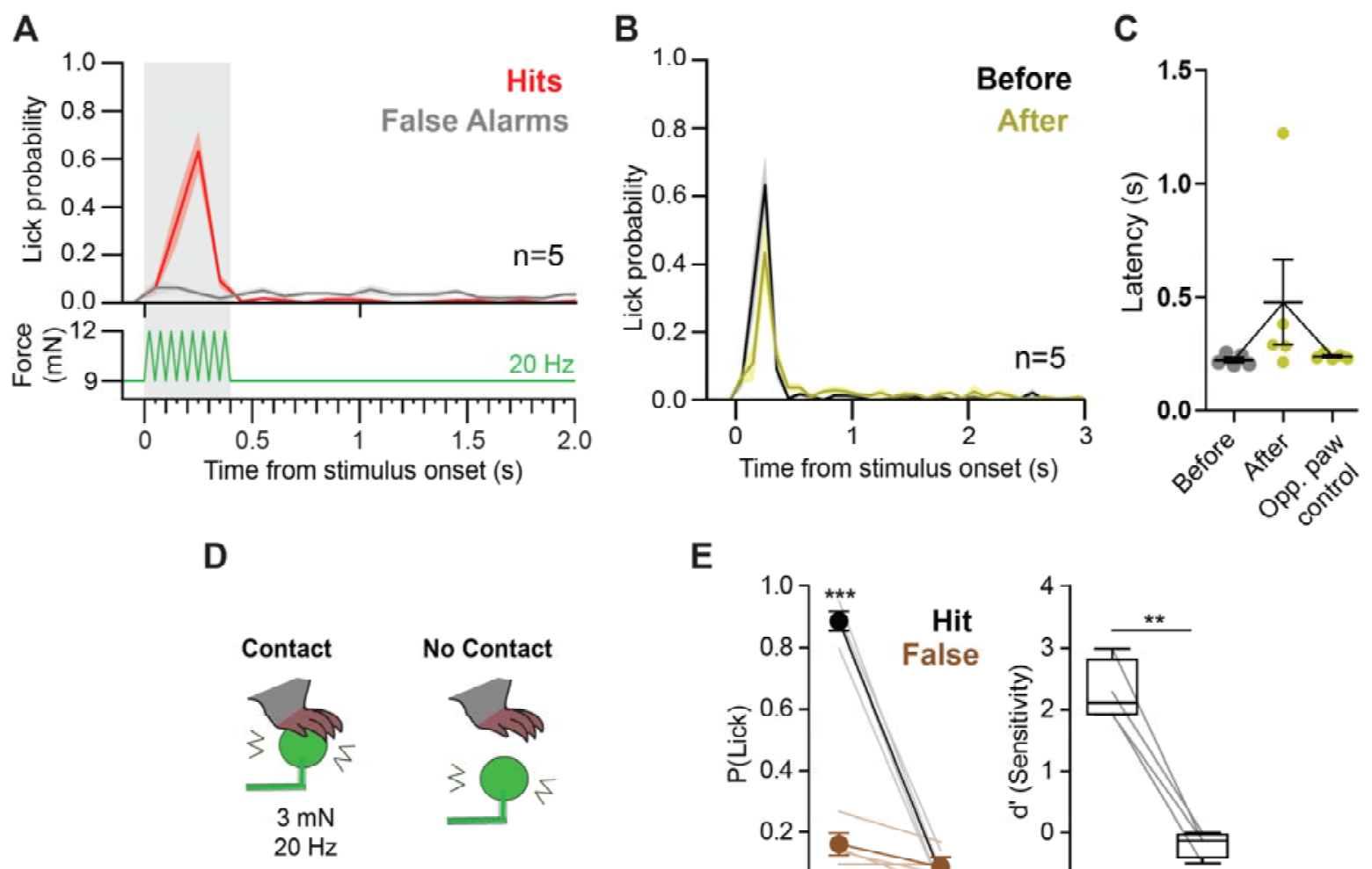

E
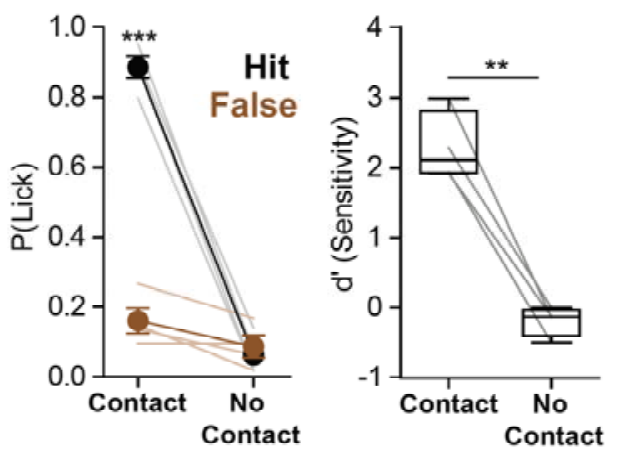

Extended Data Fig. 6 Mean lick probabilities before and after yellow light exposure (A) (Top) Peri-stimulus time histogram (PSTH) of the lick latencies of Sox10ArchT mice before optogenetic inhibition (top, $n=5$ ). Licks during stimulus trials are shown in red, and false alarms are in grey. (Bottom) stimulus trial structure. The stimulus consisted on a vibrotactile stimulus of $20 \mathrm{~Hz}$ with a baseline force of $9 \mathrm{mN}$ and an amplitude of $3 \mathrm{mN}$ (or $1.5 \mathrm{mN}$, for some mice). Stimulus duration was 0.4 seconds, identical to the window of opportunity where licks resulted in a reward. (B) PSTHs of mouse licks during stimulus trials (hits) before (black) and after the optogenetic inhibition (yellow) $(n=5)$. (C) The median latency to report the stimulus after the optogenetic inhibition was increased but this did not reach our criteria for statistical significance ( $p=0.0625$, Wilcoxon matched pairs test). (D) Control experiment where trained mice had to perform the vibrotactile detection task, with the stimulator separated a few centimeters away from the skin. This was carried out to test whether the stimulus detection was influenced by noise from the stimulator. (E) Hit and false alarm rates were statistically significant when the stimulator was in contact with the skin of Sox10-ArchT mice, but not when the stimulator made no contact (left). Sensitivity (d') was high (>1.5) when reporting the stimuli when the stimulator was in contact with the skin, but fell to chance levels $\left(d^{\prime} \sim 0\right)$ when not in contact with the skin $(n=4)$. 